\title{
The physics of fault friction: insights from experiments on simulated gouges at low shearing velocities
}

\author{
Berend A. Verberne ${ }^{1}$, Martijn P. A. van den Ende ${ }^{2}$, Jianye Chen ${ }^{3,4}$, André R. Niemeijer ${ }^{4}$, and Christopher J. Spiers ${ }^{4}$ \\ ${ }^{1}$ Geological Survey of Japan, National Institute of Advanced Industrial Science and Technology, \\ 1-1-1 Higashi, Tsukuba, Ibaraki 305-8567, Japan \\ ${ }^{2}$ Université Côte d'Azur, IRD, CNRS, Observatoire de la Côte d'Azur, Géoazur, France \\ ${ }^{3}$ Geoscience and Engineering Department, Delft University of Technology, Stevinweg 1, 2628 CN Delft, the Netherlands \\ ${ }^{4}$ Department of Earth Sciences, Utrecht University, Princetonlaan 4, 3584 CB Utrecht, the Netherlands
}

Correspondence: Berend A. Verberne (bartverberne16@hotmail.com)

Received: 12 May 2020 - Discussion started: 8 June 2020

Revised: 21 September 2020 - Accepted: 5 October 2020 - Published: 13 November 2020

\begin{abstract}
The strength properties of fault rocks at shearing rates spanning the transition from crystal-plastic flow to frictional slip play a central role in determining the distribution of crustal stress, strain, and seismicity in tectonically active regions. We review experimental and microphysical modelling work, which is aimed at elucidating the processes that control the transition from pervasive ductile flow of fault rock to rate-and-state-dependent frictional (RSF) slip and to runaway rupture, carried out at Utrecht University in the past 2 decades or so. We address shear experiments on simulated gouges composed of calcite, halitephyllosilicate mixtures, and phyllosilicate-quartz mixtures performed under laboratory conditions spanning the brittleductile transition. With increasing shear rate (or decreasing temperature), the results consistently show transitions from (1) stable velocity-strengthening ( $v$-strengthening) behaviour, to potentially unstable $v$-weakening behaviour, and (2) back to $v$ strengthening. Sample microstructures show that the first transition seen at low shear rates and/or high temperatures represents a switch from pervasive, fully ductile deformation to frictional sliding involving dilatant granular flow in localized shear bands where intergranular slip is incompletely accommodated by creep of individual mineral grains. A recent microphysical model, which treats fault rock deformation as controlled by competition between ratesensitive (diffusional or crystal-plastic) deformation of individual grains and rate-insensitive sliding interactions between grains (granular flow), predicts both transitions well. Unlike classical RSF approaches, this model quantitatively
\end{abstract}

reproduces a wide range of (transient) frictional behaviours using input parameters with direct physical meaning, with the latest progress focusing on incorporation of dynamic weakening processes characterizing co-seismic fault rupture. When implemented in numerical codes for crustal fault slip, the model offers a single unified framework for understanding slip patch nucleation and growth to critical (seismogenic) dimensions, as well as for simulating the entire seismic cycle.

\section{Introduction}

Earthquakes are the result of a sudden release of energy during rapid slip $\left(>1 \mathrm{~ms}^{-1}\right)$ along geologic fault zones in the Earth's crust or upper mantle, which generates seismic waves that can be highly destructive at the Earth's surface. Throughout history, earthquakes and associated tsunamis have claimed countless lives and caused severe material and economic damage (Guha-Sapir et al., 2016), with their impact increasing today as urban populations in tectonically active regions continue to increase. It is therefore of utmost importance to improve prognoses on the frequency, location, and magnitude of future seismic events. This demands sophisticated modelling of earthquake nucleation and dynamic rupture propagation, which in turn requires a fundamental understanding of fault sliding, or more specifically the internal fault rock shearing mechanisms that are active under in situ conditions in the Earth. 
Tectonically loaded faults can exhibit aseismic slip transients ("creep") without producing earthquakes, or else sporadic unstable slip, resulting in slow-slip events or catastrophic failure as is the case for earthquakes (Scholz et al., 1969; Peng and Gomberg, 2010). Unstable or seismic fault motion can occur at the lithosphere scale, such as along subduction zone megathrusts (Simons et al., 2011; Nishikawa et al., 2019), at the reservoir scale as in the case of humaninduced seismicity (Elsworth et al., 2016; Grigoli et al., 2018), and also within millimetre- to metre-scale samples in the laboratory (Passelègue et al., 2013; Yamashita et al., 2015; Ikari, 2019). The fault zones involved typically show a multi-scale, self-affine structure characterized by shear strain localization into narrow principal slip zones (PSZs) (Tchalenko, 1970; King, 1983; Sibson, 2003), suggesting that the rheology of the comminuted fault rock or "gouge" within PSZs controls macroscopic fault behaviour. From a mechanistic point of view, improvement of seismic hazard assessments and forecasting requires rationalization of the physics of the earthquake source as controlled by the material properties of, and deformation processes active within, sheared fault rock.

Laboratory investigations of fault slip performed under conditions relevant to Earth's upper crust are key to probing the physics of fault behaviour and seismogenesis. The mechanical data serve as direct input for empirically based numerical simulations of fault rupture (e.g. Tse and Rice, 1986; Noda and Lapusta, 2013), while post-mortem observations of recovered deformed specimens can be used to infer the underlying physical processes controlling deformation (e.g. Gu and Wong, 1994; Heilbronner and Keulen, 2006; Peč et al., 2016). In general, we can distinguish two types of laboratory fault-slip experiments. Firstly, low-velocity friction (LVF) tests are used to investigate both stable fault creep and the early (nucleation) stages of earthquake rupture. These LVF experiments are typically conducted at imposed shearing velocities $(v)$ of nanometres to micrometres or millimetres per second under fixed conditions of normal stress $\left(\sigma_{\mathrm{n}}\right)$ and temperature $(T)$. Secondly, high-velocity friction (HVF) tests are used to investigate dynamic earthquake slip processes that occur during unstable, runaway slip at slip velocities of 1 to $10 \mathrm{~m} \mathrm{~s}^{-1}$ (see Heaton, 1990). In HVF tests, frictional heating at the slipping fault interface triggers thermally activated processes such as pore fluid pressurization, phase changes, and melting, which come to dominate the evolution of fault strength (Rice, 2006; Di Toro et al., 2011; Yao et al., 2016; Rattez and Veveakis, 2020). In recent years, technological improvements in both LVF and HVF apparatuses, as well as electron beam and other instruments used to perform post-mortem micro- and nanostructural analyses, have enabled major advances in the understanding of fault rock material properties and crustal fault rheology (for reviews see De Winter et al., 2009; Viti, 2011; Niemeijer et al., 2012; Rowe and Griffith, 2015; Chen et al., 2015a).
In this paper we integrate findings from experimental, microstructural, microphysical, and numerical modelling studies of the frictional behaviour of gouge-filled faults in the low-velocity or nucleation regime conducted at Utrecht University (UU) in the past 2 decades or so. Our aim is to provide a unified view of the physics of fault friction behaviour at low velocities. We begin with a summary of key concepts and definitions, followed by a summary of the LVF experimental techniques used at UU. We go on to present key results from experiments on simulated faults composed of halitephyllosilicate and phyllosilicate-quartz mixtures, as well as of calcite. Data from these experiments consistently suggest that low velocity frictional deformation of fault gouge is controlled by competition between rate-sensitive (diffusional or crystal-plastic) deformation and rate-insensitive sliding interactions (dilatant granular flow) - competition which was already suggested on the basis of theoretical considerations by Rutter and Mainprice (1979). This forms the foundation for a unified microphysical modelling approach for lowvelocity sliding and static healing of gouge-filled faults, described in progressive detail by Niemeijer and Spiers (2007) and by Chen and Spiers (2016), for example, and referred to here for convenience as the Chen-Niemeijer-Spiers (CNS) model. We outline the principles of this model and present some applications and implications for reproducing laboratory data and numerical simulations of earthquake nucleation and the full earthquake cycle.

\section{Crustal fault strength and fault-slip models}

The strength of the Earth's crust is classically approximated using a Coulomb-type, brittle-frictional failure law representing the upper part, which abruptly gives way to ductile deformation (here used synonymously with "plastic" deformation to indicate non-dilatant permanent deformation) below $\sim 10$ to $20 \mathrm{~km}$ of depth depending on the geothermal gradient (Fig. 1) (Byerlee, 1978; Brace and Kohlstedt, 1980; Kohlstedt et al., 1995). A brittle-to-ductile transition within this depth range is consistent with geological and seismological observations of a depth interval in the crust where the majority of earthquakes nucleate, known as the "seismogenic zone" (Sibson, 1982, 1983; Meissner and Strehlau, 1982; Scholz, 1988, 2019). In the fully ductile regime, stress build-up and associated rupture nucleation are inhibited by plastic flow in shear zones, which is achieved by solid-state diffusive mass transfer and/or dislocation-mediated deformation mechanisms active at the grain scale (e.g. Karato, 2008). Within the seismogenic zone and shallower, field and laboratory observations on a wide range of fault rock types point to the concurrent operation of brittle-frictional (cataclastic) processes that depend linearly on effective normal stress and rate-sensitive plastic deformation (e.g. pressure solution, dislocation- or diffusion-mediated creep) (Wintsch et al., 1995; Holdsworth et al., 2001; Imber et al., 2008; Col- 


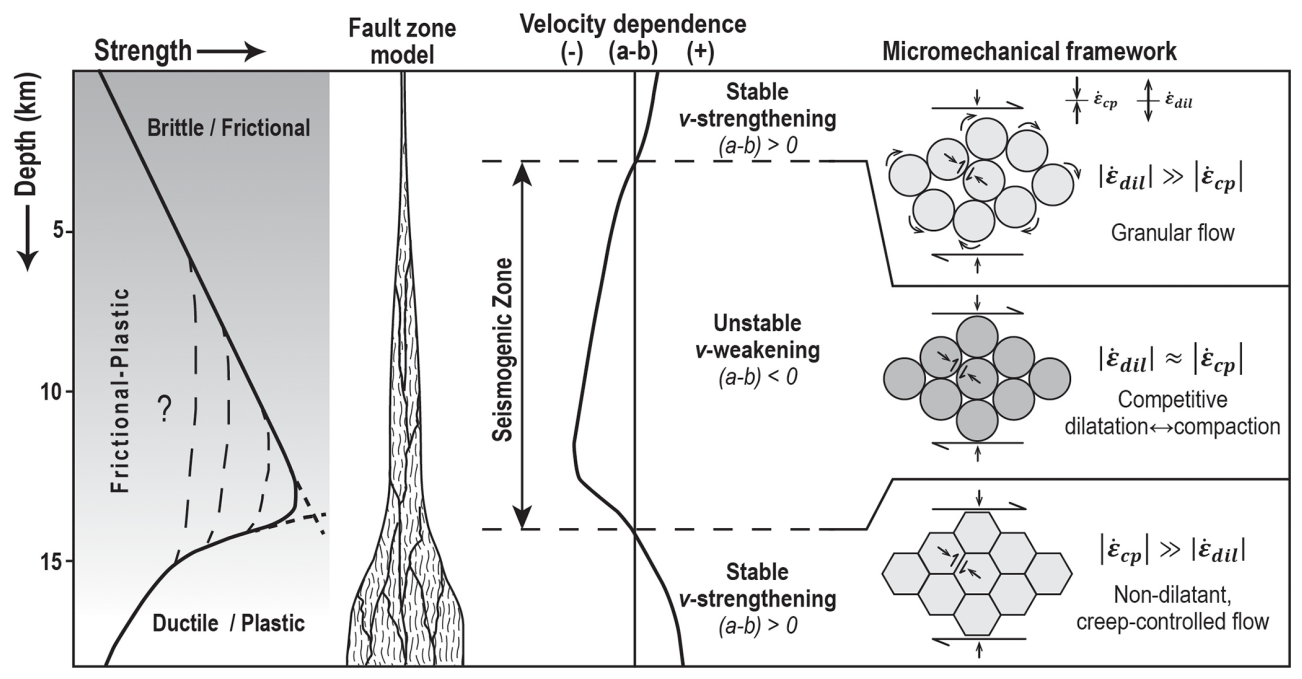

Figure 1. Conceptual model for an upper-crustal fault zone, highlighting the frictional-to-viscous transition and the seismogenic zone, which is characterized by $v$-weakening friction (i.e. $(a-b)<0)$; after Sibson $(1982,1983)$ and Scholz $(1988,2019)$. On the far right we summarize implications from the CNS model for shear of gouge-filled faults involving competition between creep-controlled compaction and dilatation by granular flow (occurring at rates of $\dot{\varepsilon}_{\mathrm{cp}}$ and $\dot{\varepsilon}_{\mathrm{gr}}$, respectively). For model details see Bos and Spiers (2002a), Niemeijer and Spiers (2006, 2007), and Chen and Spiers (2016).

lettini et al., 2011; Siman-Tov et al., 2013; Fagereng et al., 2014; Delle-Piane et al., 2018; Verberne et al., 2019). The relation between this "frictional-plastic" deformation of fault rock and seismogenesis, including the competing effects between time-sensitive and -insensitive deformation processes on failure, creep, compaction, and healing, as well as how these control the depth range of the seismogenic zone, remains the subject of intensive study in fault mechanics and fault geology (e.g. Fagereng and Den Hartog, 2016; Gao and Wang, 2017; Reber and Peč, 2018; Aharonov and Scholz, 2018, 2019; Collettini et al., 2019; Masuda et al., 2019; Hirauchi et al., 2020).

In a strictly phenomenological sense, earthquakes are analogous to the recurring frictional instability that is frequently observed in laboratory rock friction experiments known as "stick-slip" (Brace and Byerlee, 1966). Byerlee (1970) proposed that a frictional instability may arise from sudden weakening of the fault interface combined with a sufficiently low shear stiffness of the surrounding medium (experimental apparatus or host rock). However, this "slip-weakening" model does not include a mechanism for the intrinsic fault restrengthening or "healing" which is required to account for long-term, repetitive slip events (Dieterich, 1979a). To capture the time- and sliding-velocity-dependent effects of fault friction in an empirical way, Dieterich (1979a, b) proposed a rate- and "age"-dependent friction model that was later recast by Ruina (1983) in terms of the rate-and-state-dependent friction equations (RSFs), given by

$\mu=\mu_{\mathrm{sS}}^{*}+a \ln \left(\frac{v}{v^{*}}\right)+b \ln \left(\frac{v_{0} \theta}{d_{\mathrm{c}}}\right)$,

$$
\begin{aligned}
& \dot{\theta}=1-\frac{v \theta}{d_{\mathrm{c}}}, \\
& \dot{\theta}=-\frac{v \theta}{d_{\mathrm{c}}} \ln \left(\frac{v \theta}{d_{\mathrm{c}}}\right),
\end{aligned}
$$

where $\mu$ is the coefficient of friction defined as shear stress over effective normal stress (ignoring cohesion), $\mu_{\mathrm{ss}}^{*}$ is the steady-state coefficient of friction at a reference sliding velocity $v^{*}, v$ is the instantaneous slip velocity, $a$ is a parameter that quantifies the "direct effect", $b$ is the parameter that describes the "evolution effect", and $d_{\mathrm{c}}$ is a characteristic or critical slip distance over which the state variable, $\theta$, evolves (for reviews see Marone, 1998; Scholz, 1998, 2019). The state variable $\theta$ has units of time and is thought to represent the average lifetime of grain-scale asperity contacts (at steady state). The conceptual interpretation of RSF finds its origin in two observations, namely that the true area of contact of any interface is always smaller than the nominal contact area and that this area of contact changes with time (Bowden and Tabor, 1950, 1964; Rabinowicz, 1956, 1958; Dieterich and Kilgore, 1994). The equations for the state variable time derivative $(\dot{\theta}$; Eqs. $2 \mathrm{a}$ and $2 \mathrm{~b})$ embody two views of how a population of contacts may evolve during slip. Equation (2a) is sometimes called the "slowness" or "ageing" (Dieterich) law because in this formulation, the frictional contact area continues to evolve in the absence of slip, whereas in Eq. (2b), slip is needed for the state variable to evolve. Accordingly, the latter equation is called the "slip" (Ruina) law. 
In the case of steady-state sliding $\left(\mu=\mu_{\mathrm{ss}} ; \dot{\theta}=0\right)$ both the slowness and slip laws reduce to

$\mu_{\mathrm{ss}}=\mu_{\mathrm{ss}}^{*}+(a-b) \ln \left(\frac{v}{v^{*}}\right)$,

where $(a-b)$ represents a dimensionless quantity that characterizes the velocity $(v)$ dependence of the sliding surface. Ruina (1983) showed that for an instability to nucleate spontaneously and repeatedly (i.e. the case of stick-slip), the sliding surface must decrease in strength with increasing velocity and hence be $v$ weakening, characterized by $(a-b)<0$. In the opposite case $v$ strengthening occurs, characterized by $(a-b)>0$, which leads to a state of stable sliding (Ruina, 1983; Rice and Ruina, 1983). Linear stability analysis of a single-degree-of-freedom spring-slider model demonstrated a critical stiffness $K_{\mathrm{c}}$ below which sliding is unstable (Ruina, 1983).

$K_{\mathrm{c}}=\frac{(b-a) \cdot \sigma_{\mathrm{n}}^{\mathrm{eff}}}{d_{\mathrm{c}}}$

Thus, an instability may occur when the stiffness of the deforming medium falls below $K_{\mathrm{c}}$ and $(a-b)<0$. Importantly, when applied to natural faults, the $(a-b)$ value or $v$ dependence of the sliding medium is a material property of deforming rock in the fault core, and its constitutive properties are strongly affected by coupled thermo-hydro-mechanicalchemical processes in the general sense. With reference to the Earth's crust and Fig. 1, the seismogenic zone is believed to represent the depth interval where shear deformation of fault rock leads to $v$-weakening behaviour, as opposed to $v$ strengthening above and below.

The RSF approach has enabled a simple and highly successful description of laboratory rock friction behaviour over a wide range of conditions (Marone, 1998; Scholz, 1998, 2019) and is widely used in numerical simulations of the earthquake cycle (e.g. Dieterich, 1994; Lapusta and Rice, 2003; Ampuero and Rubin, 2008; Matsuzawa et al., 2010; Noda and Lapusta, 2013; Ohtani et al., 2014). However, laboratory observations and microphysical modelling show that the empirically fitted parameters appearing in the RSF equations, notably the values of $(a-b)$ and $d_{\mathrm{c}}$, are not fundamental independently measurable material constants (Ikari et al., 2016; Aharonov and Scholz, 2018). The implication is that extrapolation to natural conditions not attainable in the laboratory presents a significant source of uncertainty in numerical modelling (for a discussion see Ide, 2014; Van den Ende et al., 2018). To address this, a (micro)physically based interpretation and description of the processes controlling fault deformation is needed. Based on data from friction experiments on simulated quartz gouges at room temperature, Marone et al. (1990) hypothesized that dilatation and shear strain localization play a key role in controlling gouge shear strength and velocity dependence. Despite the key importance and application of their experimental findings and conceptual explanation (see e.g. Segall and Rice,
1995; Beeler et al., 1996), friction models derived from this pioneering work and fitted to experimental data lack a rigorous microphysical basis. An example of a mechanistically based and microstructurally founded model developed to explain $v$-dependence effects of fault rock friction, proposed by Bos, Niemeijer, and Spiers (Bos et al., 2002a; Niemeijer and Spiers, 2006, 2007), is based on the accommodation of shear deformation by a combination of frictional and plastic deformation processes. It was demonstrated that if the rates of intergranular compaction $\left(\dot{\varepsilon}_{\mathrm{cp}}\right)$ and dilatation $\left(\dot{\varepsilon}_{\mathrm{dil}}\right)$ are of comparable magnitude, or $\left|\dot{\varepsilon}_{\mathrm{dil}}\right| \approx\left|\dot{\varepsilon}_{\mathrm{cp}}\right|$, this leads to $v$-weakening behaviour, whereas under conditions in which either process dominates, stable $v$ strengthening occurs. In other words, in this framework the seismogenic zone corresponds to a depth interval where shear deformation of gougefilled faults is characterized by $\left|\dot{\varepsilon}_{\text {dil }}\right| \approx\left|\dot{\varepsilon}_{\mathrm{cp}}\right|$ (Fig. 1).

\section{Low-velocity friction (LVF) testing methods}

Research on low-velocity rock friction at UU includes faultslip experiments under pressure-temperature conditions that range from ambient surface conditions to those relevant throughout the upper $\sim 20-30 \mathrm{~km}$ of the Earth's crust. To achieve this, the ring- and direct-shear testing methods developed at UU, which are summarized below, play a critical role. For more details on the testing procedures and data analysis methods employed we refer to the various papers cited.

Ring-shear LVF experiments at UU are conducted using two distinct set-ups that are interchangeable within a single rotary shear deformation apparatus consisting of an Instron loading frame with electrically actuated ram for axial loading (application of normal stress) plus a rotation drive for imposing shear displacement onto the sample (Fig. 2a, b). The earliest ring-shear assembly, developed in the late 1990s (Bos et al., 2000a), enables simulated fault sliding tests at room temperature and at elevated normal stresses and pore fluid pressures (up to $\sim 10 \mathrm{MPa}$ ), achieving in principle unlimited rotational displacements. The simulated fault sliding rates that can be achieved depend on the arrangement of gear boxes used and range from $3 \mathrm{~nm} \mathrm{~s}^{-1}$ to up to $1 \mathrm{~cm} \mathrm{~s}^{-1}$. The assembly consists of two grooved piston rings (inner diameter $80 \mathrm{~mm}$, outer diameter $100 \mathrm{~mm}$ ) that grip a $\sim 1-2 \mathrm{~mm}$ thick, annular sample layer upon the application of normal stress, with radial confinement facilitated by tightly fitting inner and outer rings (Fig. 2a, d). This room-temperature ringshear set-up has played an important role in investigations of shear deformation of monomineralic halite and halitephyllosilicate mixtures (e.g. Takahashi et al., 2017; Van den Ende and Niemeijer, 2019), as well as of granular system dynamics using synthetic polymer and glass beads (Kumar et al., 2020).

A later "hydrothermal" ring-shear assembly was designed and commissioned in 2002-2005 (Fig. 2b, e) with the aim of enabling high-shear-strain rotary shear tests under pres- 

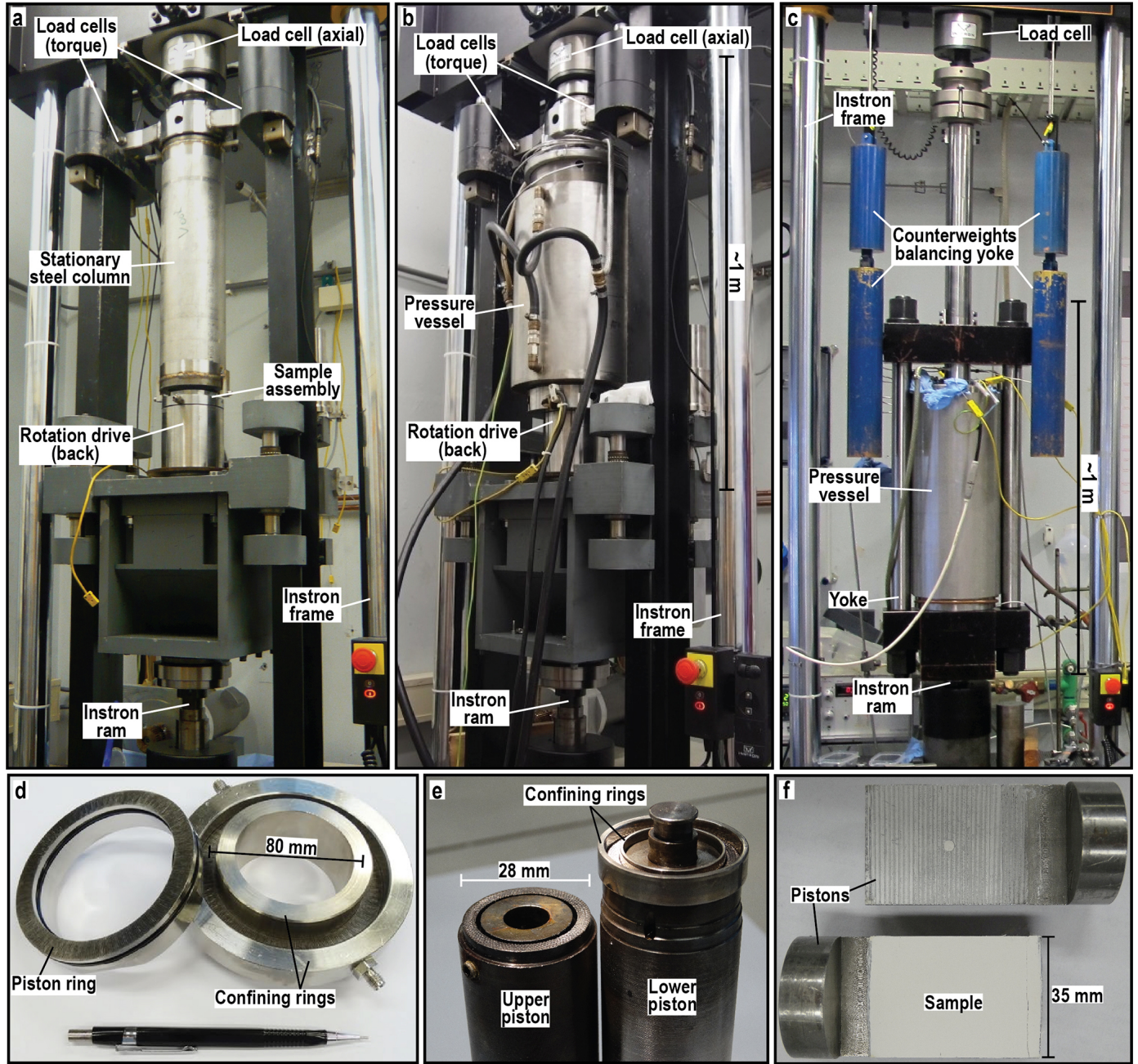

Figure 2. Apparatuses and testing assemblies used for low-velocity, ring- and direct-shear friction experiments at UU. (a, b) The roomtemperature ring-shear set-up. (b, e) The hydrothermal ring-shear set-up. (c, f) The direct-shear set-up using a triaxial pressure cell (in this case the "shuttle vessel"). Photo (a) courtesy of Miki Takahashi (Geological Survey of Japan). Photo (d) taken with publishers' permission from Van den Ende and Niemeijer (2019).

sures, temperatures, and displacement rates representative for the seismogenic reaches of crustal-scale faults and subduction megathrusts (Niemeijer et al., 2008; Van Diggelen et al., 2010; Den Hartog et al., 2012a, b). In this set-up, the piston-sample assembly is located in a pressure vessel with an internal furnace, which in turn is emplaced within the Instron frame with a rotation drive (Fig. 2b). A $\sim 1 \mathrm{~mm}$ thick sample layer is sandwiched between a set of grooved pistons and prevented from extruding by an inner confining ring with a diameter of $22 \mathrm{~mm}$ and an outer confining ring with a diameter of $28 \mathrm{~mm}$ (Fig. 2e). The vessel is pressurized with water, which has direct access to the sample, thus providing the pore fluid pressure. Experiments in this set-up can be conducted at effective normal (axial) stresses up to $300 \mathrm{MPa}$ (provided by the Instron frame), temperatures up to $700^{\circ} \mathrm{C}$, and pore fluid pressures up to $300 \mathrm{MPa}$. The rotary drive system provides simulated fault zone displacement rates rang- ing from around $1 \mathrm{~nm} \mathrm{~s}^{-1}$ to several millimetres per second. The maximum rotation or shear displacement that can be achieved is limited by the connections of the water cooling and pore fluid systems to their respective external reservoirs, but it is in practice very large $(>100 \mathrm{~mm})$. The hydrothermal ring-shear machine has been used extensively in investigations of the shear behaviour of rock compositions believed to be widespread along subduction megathrust faults (e.g. Hirauchi et al., 2013; Ikari et al., 2013; Sawai et al., 2016, 2017; Kurzawski et al., 2016, 2018; Boulton et al., 2019; Okamoto et al., 2019, 2020) and in the upper and middle continental crust (Niemeijer and Collettini, 2014; Niemeijer and Vissers, 2014; Niemeijer et al., 2016; Hellebrekers et al., 2019).

Direct-shear tests are carried out using a "conventional", externally or internally heated, oil-medium, triaxial deformation apparatus, such as that shown in Fig. 2c. Following the design of Logan et al. (1992), the direct-shear or "69" 
assembly comprises two L-shaped pistons in a jacketed faceto-face (L7) arrangement that sandwiches a cuboid sample (Fig. 2f). A soft, near-Newtonian viscous material (such as silicone putty) or soft elastomer fills the voids at the top and bottom of the assembly (Samuelson and Spiers, 2012; Sánchez-Roa et al., 2016). In the set-up used at UU, the sample measures $35 \mathrm{~mm}$ wide by $49 \mathrm{~mm}$ long with a thickness of typically $\sim 1 \mathrm{~mm}$. Direct-shear experiments can be carried out at confining pressures (normal stress) and pore pressures up to $100 \mathrm{MPa}$ and temperatures up to $150^{\circ} \mathrm{C}$, reaching shear displacements up to $\sim 6 \mathrm{~mm}$. The direct-shear assembly has proven especially useful for tests employing corrosive pore fluid compositions such as reservoir brine or $\mathrm{CO}_{2}$ (e.g. Pluymakers et al., 2014; Pluymakers and Niemeijer, 2015; Bakker et al., 2016; Hunfeld et al., 2017, 2019).

\section{Low-velocity friction experiments on simulated gouges - some case studies}

\subsection{Halite-phyllosilicate mixtures}

Bos et al. (2000a, b) and Bos and Spiers (2000, 2001, 2002a, b) employed the room-temperature ring-shear assembly (Fig. 2a, d) to investigate the shear behaviour of brinesaturated, simulated fault gouge composed of (mixtures of) halite and kaolinite. The Bos et al. experiments were carried out under conditions favouring rapid pressure solution in the halite-brine system, which is well-constrained from compaction tests and microphysical modelling (Spiers et al., 1990; Spiers and Schutjens, 1990). Kaolinite was added in varying proportions to investigate the effect on shear behaviour while simulating the presence of phyllosilicates that are observed to be widespread in natural fault zones (Wintsch et al., 1995; Holdsworth, 2004; Takeshita and El-Fakharani, 2013). The aim was to elucidate the combined role of pressure solution creep and foliation development in controlling the strength of faults in the upper crust, viewing the halitekaolinite mixtures as a mid-crustal rock analogue (see e.g. Shimamoto, 1986; Hiraga and Shimamoto, 1987; Chester and Logan, 1990). Velocity $(v)$ and normal stress $\left(\sigma_{\mathrm{n}}\right)$ stepping experiments (Fig. 3a), as well as post-mortem microstructural analyses which revealed a classical foliated mylonitic (i.e. phyllonitic) microstructure (Fig. 3b), pointed to frictional-viscous flow in the case of halite-kaolinite mixtures but to purely frictional behaviour in the case of the monomineralic endmember gouges (Fig. 3a). Based on these results, Bos and Spiers $(2001,2002 a)$ proposed a micromechanical model for the combined effect of frictional sliding on phyllosilicate folia, pressure solution of halite clasts, and dilatation on the foliation (Fig. 3c). This model offered the first microstructurally based interpretation for $v$ strengthening frictional-viscous flow of gouge-filled faults.

Niemeijer and Spiers (2005) refined the Bos and Spiers model by incorporating effects of plasticity of phyllosili- cate folia and a distributed grain size. Moreover, their experiments used muscovite instead of kaolinite and covered a wider range of sliding velocities. Their experiments revealed a $v$-weakening regime beyond $v=1 \mu \mathrm{m} \mathrm{s}^{-1}$ (Fig. 3d), characterized by a strong increase in porosity with increasing $v$ (Niemeijer and Spiers, 2005, 2006). Compared with $v$-strengthening samples, those deformed under $v$-weakening conditions showed a chaotic, cataclastic microstructure (Fig. 3e). On this basis it was hypothesized that $v$ weakening results from competition between dilatation by granular flow and intergranular compaction by pressure solution (Niemeijer and Spiers, 2006). This microphysical model concept was further developed and quantified to enable calculation of steady-state shear strength in the $v$ weakening regime based on physically meaningful input parameters such as the kinetics parameters for pressure solution, porosity, and dilation angle for granular flow (Niemeijer and Spiers, 2007) (Fig. 3f). By combining the model for frictional-viscous flow with that for $v$-weakening frictional sliding, the lab-observed transition from $v$ strengthening to weakening with increasing shear displacement rate in halitephyllosilicate mixtures could be accurately reproduced.

\subsection{Phyllosilicate-quartz mixtures}

The experiments using halite-phyllosilicate mixtures as a fault rock analogue system trigger the inevitable question of whether the same processes and mechanical behaviour really occur within crustal faults. Specifically, the microphysical models developed for $v$ dependence of gouge-filled faults required testing for real crustal fault rock types under conditions relevant for the seismogenic zone. With this in mind, Den Hartog et al. (2012a, b, 2013, 2014) investigated the frictional behaviour of phyllosilicate-quartz gouge mixtures using the hydrothermal ring-shear apparatus (Fig. 2b, d) under $P-T$ conditions broadly representative for the seismogenic reaches of a subduction zone megathrust. The samples consisted mainly of $465: 35$ illite-quartz gouge mixtures, but muscovite-quartz gouge mixtures and clay-rich samples derived from the Nankai Oceanic Drilling Project (Leg 190) were also tested. Experiments were carried out at effective normal stresses $\left(\sigma_{\mathrm{n}}^{\text {eff }}\right)$ ranging from 25 to $200 \mathrm{MPa}$, at pore fluid pressures $\left(P_{\mathrm{f}}\right)$ of 0 (dry) to $200 \mathrm{MPa}$, and temperatures $(T)$ of 100 to $600{ }^{\circ} \mathrm{C}$. The data consistently showed $v$ strengthening behaviour at relatively low temperatures (up to $\sim 250-350^{\circ} \mathrm{C}$, Regime 1), $v$ weakening at intermediate temperatures $\left(\sim 250-500^{\circ} \mathrm{C}\right.$, Regime 2$)$, and again $v$ strengthening at the highest temperatures investigated $\left(>500^{\circ} \mathrm{C}\right.$, Regime 3) (Fig. 4a). Such "three-regime" $v$ dependence with increasing temperature has been observed for granite (Blanpied et al., 1991, 1995) and gabbro (He et al., 2007) gouges, but Den Hartog and co-workers were the first to report this for a realistic megathrust fault rock composition. The temperature range in which $v$ weakening was reported is broadly consistent with the temperature-depth range of the subduc- 

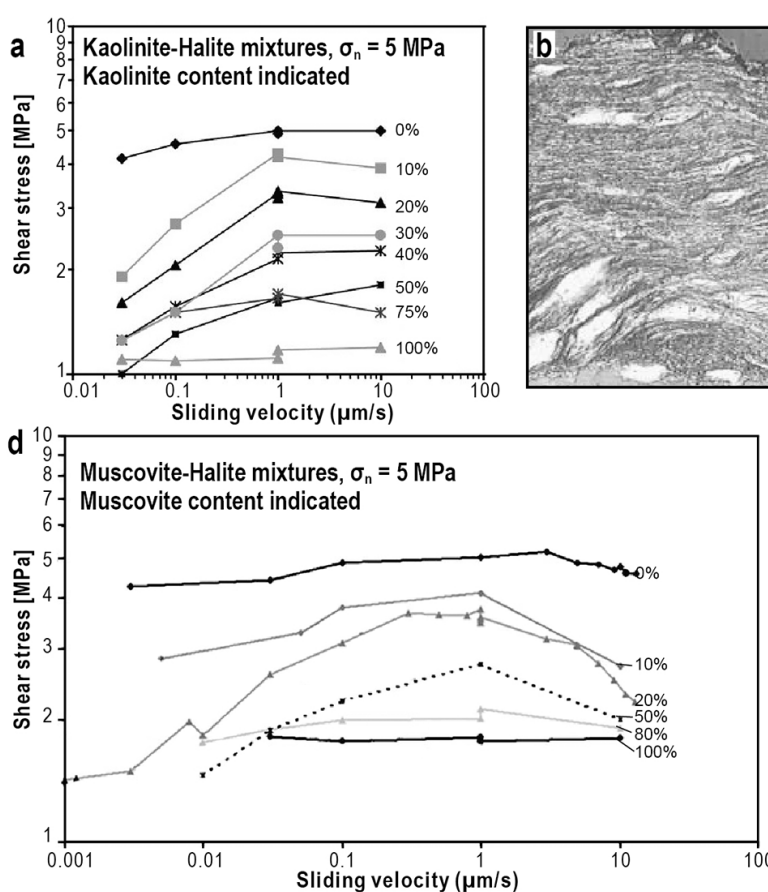
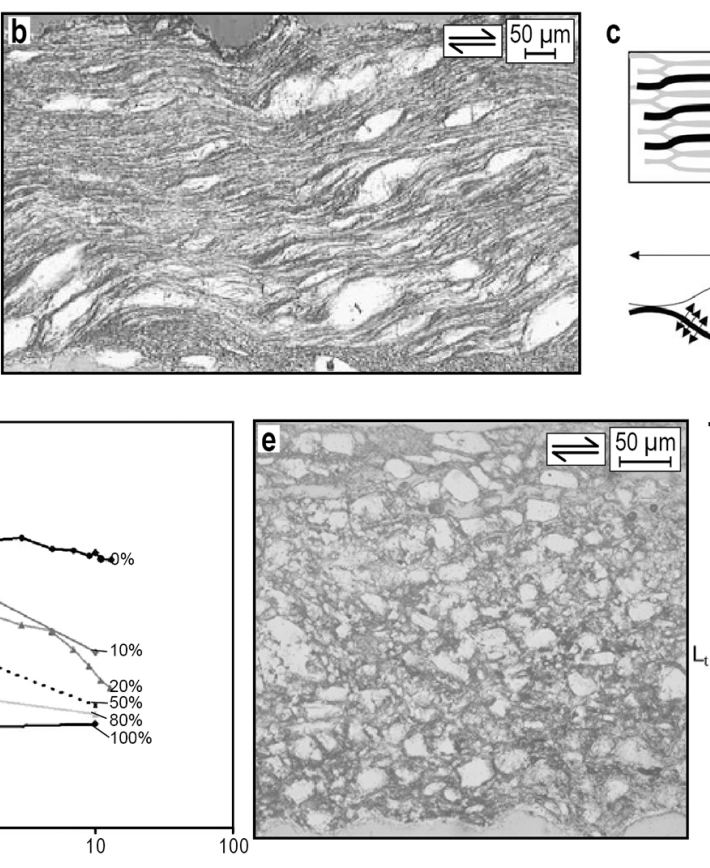
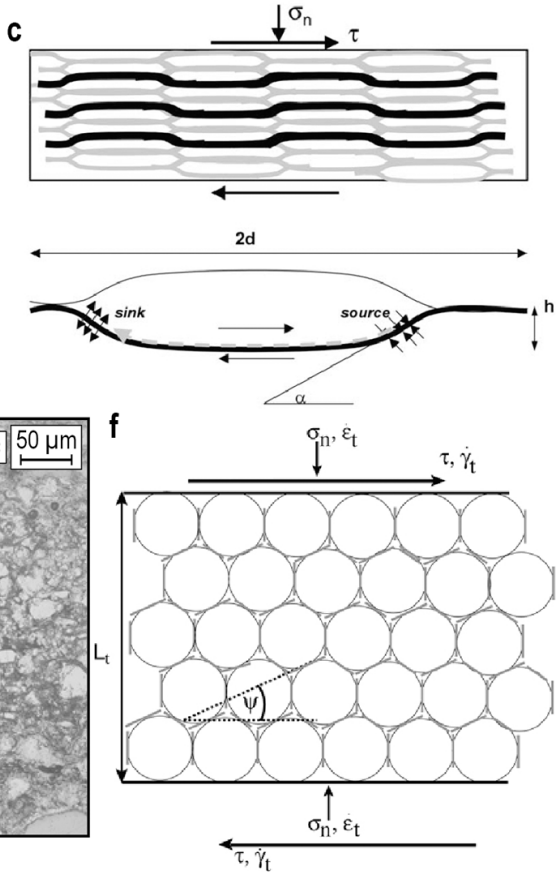

Figure 3. Data from ring-shear experiments on halite-phyllosilicate mixtures conducted at room temperature. (a, b) Halite-kaolinite mixtures deformed in the $v$-strengthening frictional-viscous regime (adapted from Bos et al., 2000b - license no. 4656341028661). (c) Model microstructure for $v$-strengthening frictional-viscous flow (taken with publisher's permission from Bos and Spiers, 2002a). $\sigma_{\mathrm{n}}$ : normal stress; $\tau$ : shear stress; $\alpha$ : the angle between the leading edge of the halite grain and the horizontal; $h$ : amplitude of the foliation; $d$ : grain size (long axis). (d) Velocity dependence effects in halite-muscovite gouges (adapted from Niemeijer and Spiers, 2006 - license no. 4656330624652), with (e) a sample deformed in the $v$-weakening regime (taken with publisher's permission from Niemeijer and Spiers, 2005). (f) Model microstructure for $v$-weakening granular flow (taken with publisher's permission from Niemeijer and Spiers, 2007). $\dot{\varepsilon}_{\mathrm{t}}$ : macroscopic normal strain rate; $\dot{\gamma}_{\mathrm{t}}$ : macroscopic shear strain rate; $\psi$ : dilatation angle; $L_{\mathrm{t}}$ : thickness of the deforming zone; other symbols are the same as in (c).

tion seismogenic zone such as in Nankai (Hyndman et al., 1997; Yoshioka et al., 2013; Okamoto et al., 2019).

The above observations on illite-quartz and muscovitequartz gouges were explained first qualitatively and later using a quantitative model based on the Niemeijer and Spiers (2007) approach, but employing a phyllosilicatedominated model microstructure (Fig. 4b) (Den Hartog and Spiers, 2013, 2014; see also Noda, 2016). The change in the sign of $(a-b)$ with increasing temperature was proposed to occur due to changes in the role of thermally activated deformation of the quartz clast phase (by stress corrosion cracking and/or pressure solution) versus that of athermal granular flow of the mixture accompanied by dilatation (Fig. 4b). On the basis of widespread experimental observations (Ikari et al., 2011), expected $v$-strengthening effects of frictional slip within the phyllosilicate matrix and foliation were taken into account. Assuming pressure solution as the controlling thermally activated process, the experimentally observed threeregime $v$ dependence could be reproduced. On the other hand, Niemeijer (2018) recently showed a good match between data from constant $-v$ shear experiments using $80: 20$ quartz-muscovite gouges and predictions of the Bos-SpiersNiemeijer model for frictional-viscous flow (Bos and Spiers, 2002a; Niemeijer and Spiers, 2005) (Fig. 4c). Regardless of the details of the model used, the results of Den Hartog and co-workers, and those of Niemeijer (2018), imply that shear strain accommodation involving competition between ratesensitive (thermally activated creep of clast phases) and rateinsensitive processes (dilatant intergranular sliding) plays a key role in controlling $v$-dependent frictional and frictionalviscous flow of phyllosilicate-quartz mixtures.

\subsection{Calcite}

Motivated by the frequency of destructive earthquakes in tectonically active carbonate-bearing terranes such as the Apennines (Italy) and the Longmen Shan (China), Verberne et al. (2013, 2014a, b, 2015) and Chen et al. (2015b, c) investigated the frictional behaviour of simulated calcite(-rich) fault gouge. Initial experiments employing the direct-shear assembly (Fig. 2c, f) were conducted at $T=20-150^{\circ} \mathrm{C}, \sigma_{\mathrm{n}}^{\text {eff }}=$ $50 \mathrm{MPa}$, and a pore water pressure $P_{\mathrm{f}}=10 \mathrm{MPa}$ or else under room-dry conditions. Dry and wet velocity stepping $\left(v=0.1,1,10 \mu \mathrm{m} \mathrm{s}^{-1}\right)$ experiments consistently showed a thermally activated transition from $v$ strengthening to weakening at $80-100^{\circ} \mathrm{C}$ (Fig. 5a, b). Furthermore, results from fault healing ("slide-hold-slide" or SHS) tests pointed to an 

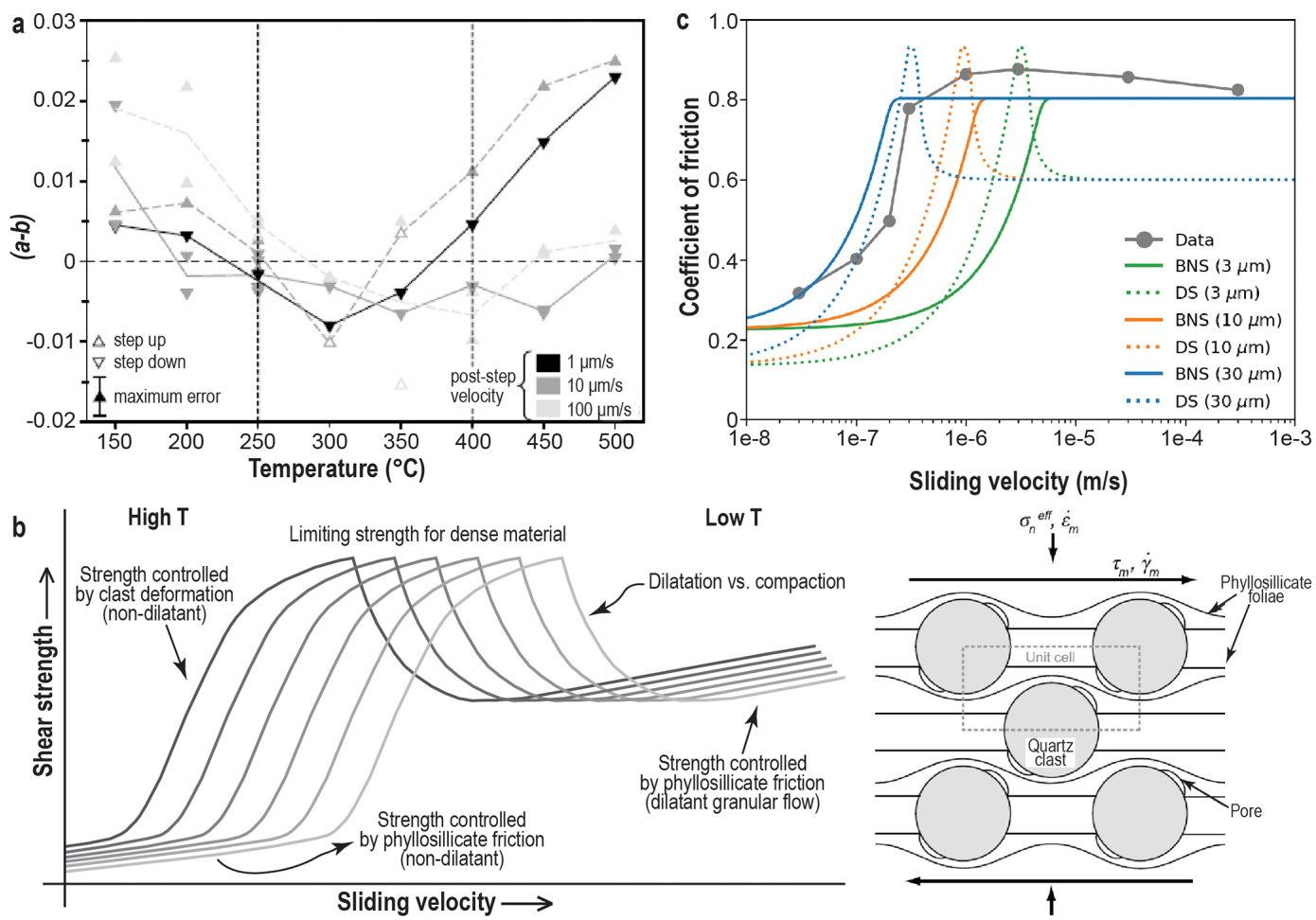

Figure 4. Data from hydrothermal ring-shear experiments on quartz-phyllosilicate mixtures. (a) Three regimes of $v$ dependence seen in experiments on illite-quartz mixtures (taken with publisher's permission from Den Hartog and Spiers, 2014). (b) Conceptual interpretation of quartz-phyllosilicate strength evolution with sliding velocity and temperature (left) (taken with publisher's permission from Den Hartog and Spiers, 2013) and the model microstructure envisioned by Den Hartog and Spiers (2014) (DS model, right). (c) Coefficient of friction at steady state against sliding velocity including data from constant- $v$ experiments by Niemeijer (2018) in grey. The coloured curves are generated using the model for frictional-viscous deformation (BNS, solid lines) (Bos and Spiers, 2002a; Niemeijer and Spiers, 2005) and using the DS model (dashed lines) for different nominal grain sizes as indicated. The peaks mark a transition from $v$ strengthening to $v$ weakening (taken with publisher's permission from Niemeijer, 2018).

important role for the presence of (pressurized) pore water. Dry samples exhibited classical "Dieterich-type" healing behaviour (Dieterich, 1978), characterized by a transient peak in shear resistance after each hold period with no effects on steady-state frictional strength. By contrast, wet experiments showed (i) an increase in apparent steady-state friction upon re-sliding after a hold period (note $\Delta \mu_{\mathrm{r}}$ in Fig. 5a, inset), and (ii) a pronounced increase in $(a-b)$ after the SHS stage (Chen et al., 2015b, c). Verberne et al. (2015) extended the temperature range of shear tests on simulated calcite gouge to $600{ }^{\circ} \mathrm{C}$ using the hydrothermal ring-shear apparatus and employing a constant effective normal stress of $50 \mathrm{MPa}$. The results showed a three-regime trend in $(a-b)$ values with increasing temperature, reminiscent of that predicted by the Den Hartog and Spiers model (i.e. the derivative of the curves in Fig. 4b, sketched in the inset to Fig. 5b) (Den Hartog and Spiers, 2013, 2014; Verberne et al., 2015).

Regardless of the large changes in $(a-b)$ observed in LVF experiments on simulated calcite gouge, the microstructures formed at temperatures up to $550^{\circ} \mathrm{C}$ consistently showed localization into at least one narrow $(<100 \mu \mathrm{m})$ boundary- parallel shear band. At low temperatures $\left(<150{ }^{\circ} \mathrm{C}\right)$, boundary shears represent a porous, sheet-like volume of calcite nanocrystallites (grain size down to $5 \mathrm{~nm}$ ) that are locally arranged in dense patches composed of $\sim 100 \mathrm{~nm}$ wide spherical grains and fibres (Fig. 5c, inset) (Verberne et al., $2014 \mathrm{a}, \mathrm{b}, 2019)$. Towards higher temperatures $\left(400-550^{\circ} \mathrm{C}\right)$ the shear band is composed of linear, cavitated arrays of polygonal grains $(\sim 0.3-1 \mu \mathrm{m}$ in size), suggestive of incomplete grain boundary sliding and (possible post-test) grain growth (Fig. 5d) (Verberne et al., 2017). The nano- and microcrystalline boundary shears developed in experiments carried out at $\leq 550^{\circ} \mathrm{C}$ showed a strong crystallographic preferred orientation (Verberne et al., 2013, 2017). Somewhat surprisingly, the post-mortem calcite gouge microstructures resemble those formed in HVF experiments using simulated gouge material of similar compositions (Smith et al., 2013; De Paola et al., 2015; Rempe et al., 2017; Pozzi et al., 2019). Above $550^{\circ} \mathrm{C}$, a more homogeneous (non-localized), plastically deformed, and recrystallized microstructure is observed, consistent with flow controlled by dislocation and 

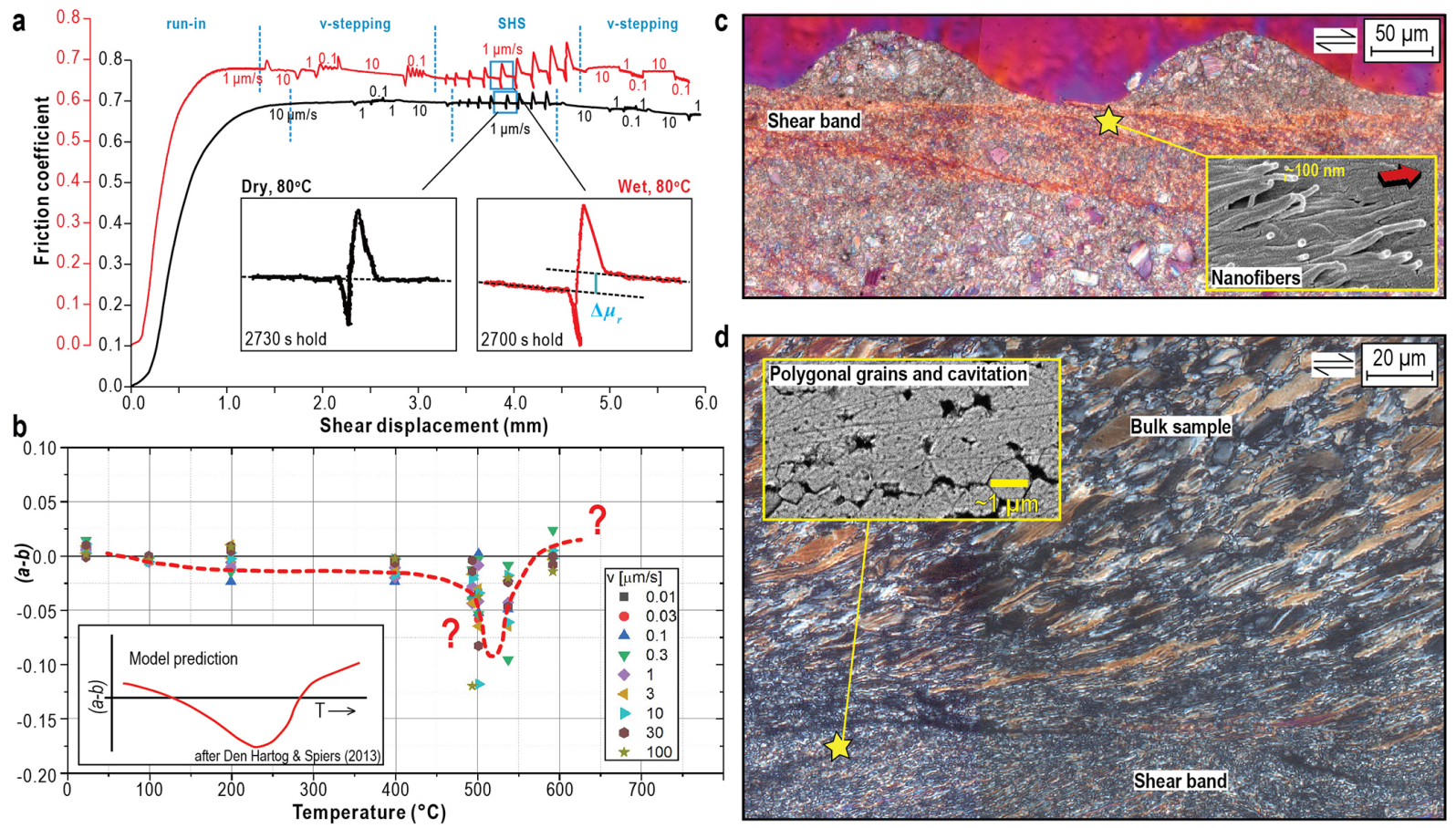

Figure 5. Data from shear experiments on simulated calcite fault gouge. (a) Direct-shear tests conducted at an effective normal stress $\left(\sigma_{\mathrm{n}}^{\text {eff }}\right)$ of $50 \mathrm{MPa}$, at $80^{\circ} \mathrm{C}$, under lab-dry conditions (black curve), and using a pore fluid pressure of $10 \mathrm{MPa}$ (red curve). The test includes velocity stepping (VS) and slide-hold-slide (SHS) sequences; $\Delta \mu_{\mathrm{r}}$ indicates residual healing after a hold period (adapted from Chen et al., 2015b license no. 4658610579860). (b) Velocity dependence $(a-b)$ against temperature for experiments conducted up to $600{ }^{\circ} \mathrm{C}$ at $\sigma_{\mathrm{n}}^{\text {eff }}=50 \mathrm{MPa}$ using the hydrothermal ring-shear set-up (data from Verberne et al., 2015). (c, d) Cross-polarized, transmitted light micrographs of samples sheared in $v$-stepping experiments conducted nominally dry at room temperature (c) and wet at $500{ }^{\circ} \mathrm{C}$ (d). Inset in (c) shows nanofibres observed on split sample fragments after an experiment. Inset in (d) highlights cavitated arrays of polygonal grains.

possibly diffusional deformation mechanisms (Verberne et al., 2015, 2017; Chen et al., 2020b).

\section{The Chen-Niemeijer-Spiers microphysical model for the shear of gouge-filled faults}

Inspired by the modelling work of Bos, Niemeijer, Den Hartog, and Spiers (Figs. 3, 4), as well as the observations on monomineralic calcite gouge (Fig. 5), Chen and Spiers (2016) developed a more general microphysical model for (localized) shear deformation of gouge-filled faults. This model employs rate-strengthening grain boundary friction plus standard equations for pressure solution creep and covers both steady-state and transient gouge shearing behaviour. It is capable of reproducing results from $v$ stepping and SHS tests using physically based, independently measured input parameters. In the following, we describe the main features of this Chen-Niemeijer-Spiers (CNS) model.

\subsection{Model outline}

The CNS model assumes an idealized geometry for fault gouge that consists of a densely packed, two-dimensional array of cylinders or spheres while allowing for localized de-
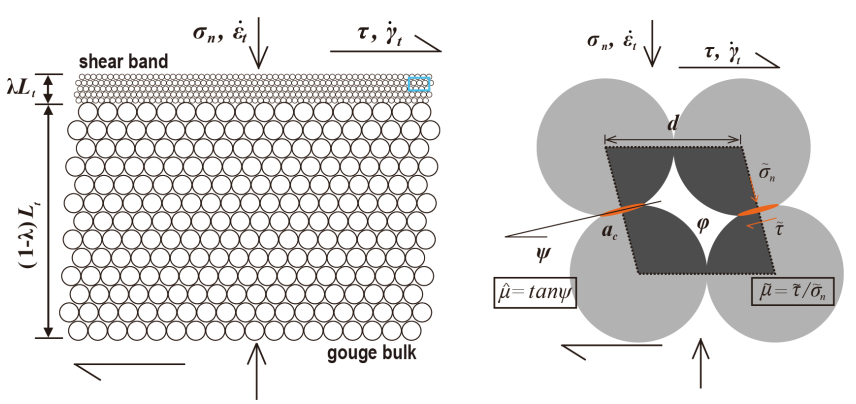

Figure 6. Gouge layer geometry assumed in the Chen-NiemeijerSpiers (CNS) model. After Chen and Spiers (2016).

formation in a boundary-parallel shear band located at the margin of a bulk gouge zone (Fig. 6). The shear band and the bulk are represented by the same grain packing geometry but with different nominal grain diameters internally. Deformation of the gouge layer is controlled by parallel processes active within each zone: that is, dilatant granular flow plus a creep process such as intergranular pressure solution (IPS). The model considers frictional energy dissipation for a constant grain size and shear band thickness, ignoring (de)localization, grain rolling, and comminution (cataclasis, mi- 
crocracking). The governing constitutive equations are derived from kinematic, energy, and entropy considerations (Chen and Spiers, 2016);

$\tau=\sigma_{\mathrm{n}}^{\operatorname{eff}} \frac{\tilde{\mu}+\tan (\psi)}{1-\tilde{\mu} \tan (\psi)}$,

$\tilde{\mu}=\tilde{\mu}^{*}+a_{\tilde{\mu}} \ln \left(\frac{\dot{\gamma}_{\mathrm{gr}}}{\dot{\gamma}_{\mathrm{gr}}^{*}}\right)$,

$\frac{\dot{\varphi}}{(1-\varphi)}=-\dot{\varepsilon}_{\mathrm{pl}}+\dot{\gamma}_{\mathrm{gr}} \tan \psi$,

where $\tau$ is shear stress, $\sigma_{\mathrm{n}}^{\text {eff }}$ is the effective normal stress, and $\varphi$ is the shear band porosity. Further, $\dot{\gamma}$ and $\dot{\varepsilon}$ are respectively the shear and normal strain rates, where the subscript "pl" indicates time-dependent plastic creep and "gr" indicates granular flow. Equation (5a) represents a "friction law", in which shear resistance is expressed in terms of grain boundary friction $\tilde{\mu}$ and the resistance due to intergranular dilatation, $\tan (\psi)$. Here, $\psi$ is the mean dilatancy angle of the shearing grain pack (Fig. 6). An intrinsically $v$ strengthening, cohesionless grain boundary slip criterion is adopted (Eq. 5b), where $a_{\tilde{\mu}}$ is a strain-rate-dependent coefficient and $\tilde{\mu}^{*}$ is the grain boundary friction coefficient at a reference shear strain rate $\dot{\gamma}_{\mathrm{gr}}^{*}$. Equation (5c) captures the evolution of porosity and deformation in the fault-normal direction (i.e. volumetric strains). Granular flow implies dilatation, or $\dot{\varepsilon}_{\mathrm{gr}}=-\dot{\gamma}_{\mathrm{gr}} \tan (\psi)$ (Paterson, 1995; Gudehus, 2011). The evolving "state" variable in the CNS model is porosity (Eq. 5c), which is clearly physically measurable and microstructurally quantifiable, as opposed to that characterizing the classical RSF equations (Eqs. 1, 2). To capture transient frictional behaviours such as those occurring upon a perturbation in displacement rate, the deforming gouge plus elastic surrounding (testing apparatus or host rock) is modelled as a spring-slider system assuming zero inertia. Recently, Chen et al. (2019) extended the CNS model to seismic slip rates $\left(\sim 1 \mathrm{~m} \mathrm{~s}^{-1}\right)$ by incorporating superplastic flow activated by frictional heating (De Paola et al., 2015). This refined model is capable of predicting not only low-velocity frictional behaviour but also (the transition to) rapid dynamic weakening effects frequently seen in high-velocity friction experiments (see Di Toro et al., 2011).

\subsection{Comparison with lab data and model predictions}

The CNS model has been strikingly successful in reproducing mechanical behaviours observed in laboratory fault-slip experiments (Figs. 7a, b) (Chen and Spiers, 2016; Chen and Niemeijer, 2017; Chen et al., 2017, 2019, 2020; Hunfeld et al., 2019, 2020a, b). In order to reproduce experimental data, the parameters appearing in Eqs. (5a)-(5c) are implicit from the testing configuration used, experimentally derived values, or values derived from post-mortem microstructural analysis. The model shows favourable consistency with laboratory observations, predicting a dependence of the steady- state friction coefficient on sliding velocity, including a transition from $v$ weakening to strengthening with increasing $v$ (Fig. 7a). Transient strength data upon steps in displacement rate and decaying strength oscillations are also reproduced well (Fig. $7 \mathrm{~b}-$ see the step from 1 to $0.1 \mu \mathrm{m} \mathrm{s}^{-1}$ ). When applied over a wide range of sliding velocities, the CNS model output for the steady-state friction coefficient essentially represents a flow-to-friction profile (Fig. 7c), characterized by transitions with increasing $v$ from $v$ strengthening, to weakening, back to $v$ strengthening, and finally $v$ weakening associated with dynamic thermal weakening at high velocities (Chen and Niemeijer, 2017; Chen et al., 2019). These $v$ dependence transitions are accompanied by marked changes in mean porosity (bottom Fig. 7c). In the intermediate velocity weakening regime, the mean porosity increases with increasing $v$ to relatively high values; however, this decreases to much lower levels when creep becomes the dominant deformation mechanism. Since decreasing shear strain rate in the model is, to some extent, equivalent to an increase in temperature (Bos and Spiers, 2002a; Tenthorey and Cox, 2006; Den Hartog and Spiers, 2013), the model can also be used to predict $v$-dependence transitions with increasing temperature.

Using the CNS model, the above "critical" sliding velocities or temperatures marking transitions in fault gouge $v$ dependence can be derived theoretically. Furthermore, the model can be used to derive analytical solutions for the RSF parameters $a, b$, and $d_{\mathrm{c}}$ as functions of gouge material properties (solid solubility, activation volume), microstructural parameters (grain size, porosity, shear band thickness), and experimental conditions (temperature, effective normal stress, imposed slip rate) (Chen et al., 2017). This shows that $d_{\mathrm{c}}$ scales with shear band thickness (consistent with Marone and Kilgore, 1993), while varying only slightly with slip velocity, and that the equivalent slip distance in response to large perturbations, $d_{0}$, increases with the size of the velocity perturbation (Fig. 8a). Furthermore, Van den Ende et al. (2018) showed that the process zone size $\left(h_{\mathrm{cr}}\right)$ for a propagating rupture can be expressed as $h_{\mathrm{cr}}=d_{\mathrm{c}} G / b \sigma_{\mathrm{n}}$, where $G$ is the shear modulus of the elastic medium. This result is consistent with the process zone size or "nucleation length" $L_{\mathrm{b}}$ derived from RSF analyses (Rubin and Ampuero, 2005). Similarities between the RSF and CNS models are also apparent when applying classical fault stability theory (see Eq. 4) (Ruina, 1983; Gu et al., 1984). Specifically, varying the stiffness $K$ enables simulation of a wide range of transient frictional behaviours frequently seen in laboratory experiments (Chen and Niemeijer, 2017), including stable sliding, healing, attenuating or self-sustained (quasi-static) oscillations, and stick-slip (Fig. 8b) (see Baumberger et al., 1994; Leeman et al., 2016). The transition from stable to unstable behaviour occurs at the critical stiffness $K=K_{\mathrm{c}}$. The model similarly implies that the transition at low shearing rates, from fully ductile $v$-strengthening behaviour to dilatant $v$ weakening (first peak in Fig. 7c), marks the point at which 
$v$ weakening causes acceleration and, ultimately, a dynamic instability (second peak in Fig. 7c).

Significantly, stick-slip oscillations generated using the CNS model can also be reproduced using numerical discrete element modelling (DEM) of gouges subject to direct shear, accommodated by concurrent granular flow and intergranular pressure solution (IPS) (Van den Ende and Niemeijer, 2018). Even though the detailed mechanics and assumptions used in DEM are dramatically different from those underlying the CNS model, the concept of shear strain accommodation involving competition between dilatant granular flow and IPS is sufficiently robust to reproduce a wide range of frictional sliding modes.

\section{Earthquake cycle simulations using the CNS model}

\subsection{Empirical and physically based earthquake cycle simulations}

Laboratory observations of fault rock deformation can be thought of as measurements of a point along a fault characterized by a certain state of stress and thermodynamic conditions. Analytical models such as the CNS model offer a quantitative description of the mechanical behaviour of the fault at that point. Numerical simulations are indispensable for upscaling these "point measurements" to the scale of the Earth's crust. In simulations of earthquake rupture nucleation and dynamic propagation, a section of crust or fault is usually discretized such that the continuum is represented by a collection of points, the behaviour of each of which is described with a constitutive relation. Over the last few decades, the rate-and-state friction model has been the preferred choice for numerical simulations of fault slip, which has led to important insights into the spectrum of fault-slip behaviour (Shibazaki and Iio, 2003; Hawthorne and Rubin, 2013), earthquake rupture propagation and arrest (Tinti et al., 2005; Noda and Lapusta, 2013; Lui and Lapusta, 2016), and the relation between the earthquake source and seismological and geodetic observations (Kaneko et al, 2010; Thomas et al., 2017; Barbot, 2019; Ulrich et al., 2019). However, a major challenge that remains is relating laboratory data on RSF parameters to fault rheology at depth in the Earth's crust.

Physics-based models for fault slip such as the CNS model provide a transparent origin of the constitutive parameters used, so when employed in numerical simulations a substantial portion of epistemic uncertainty is eliminated. Conveniently, in the case of the CNS model, its numerical implementation into a seismic cycle simulator (QDYN in the study of Van den Ende et al., 2018; see Luo et al., 2017) is similar to that of the RSF equations, implying that it is compatible with existing codes for seismic cycle and dynamic rupture simulations. Furthermore, the modular nature of the CNS model enables specific microscale deformation mechanisms to be incorporated based on microstructural observa- tions of lab-deformed and natural samples, offering a framework for studying the interaction between time-sensitive and -insensitive deformation mechanisms (i.e. creep and granular flow). That said, more work is needed to learn about and quantitatively capture the microphysical processes controlling deformation across the entire fault-slip velocity spectrum, covering quasi-static deformation in interseismic periods and dynamic rupture.

\subsection{Insights into the physics of fault behaviour from CNS-based simulations}

Because the dynamics of the CNS model are different from rate-and-state friction (RSF), CNS-based numerical simulations of fault slip may lead to new insights into the physics of fault deformation. In a comparison between RSF- and CNS-based simulations, Van den Ende et al. (2018) found that fault strength evolution near steady state is practically identical but that the behaviour far from steady state differs; hence, there are differences between seismic cycle predictions. Specifically, in the absence of high-velocity dynamic weakening mechanisms, instead of producing seismic events with large co-seismic slip as expected from RSF-based simulations, CNS-based simulations produce earthquakes with limited co-seismic displacement (Fig. 9). The latter can be explained by the transition from $v$ weakening to strengthening with increasing slip rate implicit in the CNS model (see Fig. 7c), which effectively slows down dynamic rupture. In other words, the transition with increasing $v$ (or decreasing $T$ ) from $v$ weakening to strengthening constitutes a potential mechanism for the generation of slow earthquakes (as previously speculated upon by Rubin, 2011; see also Bürgmann, 2018).

The emergence of slow ruptures in numerical simulations is closely related to the nucleation of a frictional instability, which, in the CNS model, occurs near the transition from the ductile creep regime ( $v$ strengthening) to the dilatant granular flow regime ( $v$ weakening) (Fig. 7c). In numerical simulations that employ classical RSF and an ageing law (Eqs. 1 and 2a), a rupture becomes dynamic when it exceeds a length scale that is proportional to the nucleation length $L_{\mathrm{b}}(\mathrm{Am}$ puero and Rubin, 2008; Rubin, 2008). When $L_{\mathrm{b}}$ approaches the size of the fault, the rupture is unable to fully accelerate to co-seismic slip rates, causing a slow-slip event or slow earthquake (Rubin, 2008). For the CNS model, equivalent expressions for $L_{\mathrm{b}}$ can be obtained that apply to rupture nucleation near the ductile-frictional transition. However, in the case of a transition from $v$ weakening to $v$ strengthening, the transition from slow slip to fast slip is no longer accurately described by traditional estimates of the nucleation length using constant rate-independent coefficients. Rather, a more detailed fracture mechanics approach (as adopted by Hawthorne and Rubin, 2013, for a modified RSF framework) may shed new light on the parameters controlling earthquake and slow-slip nucleation, as well as of the thermodynamic 

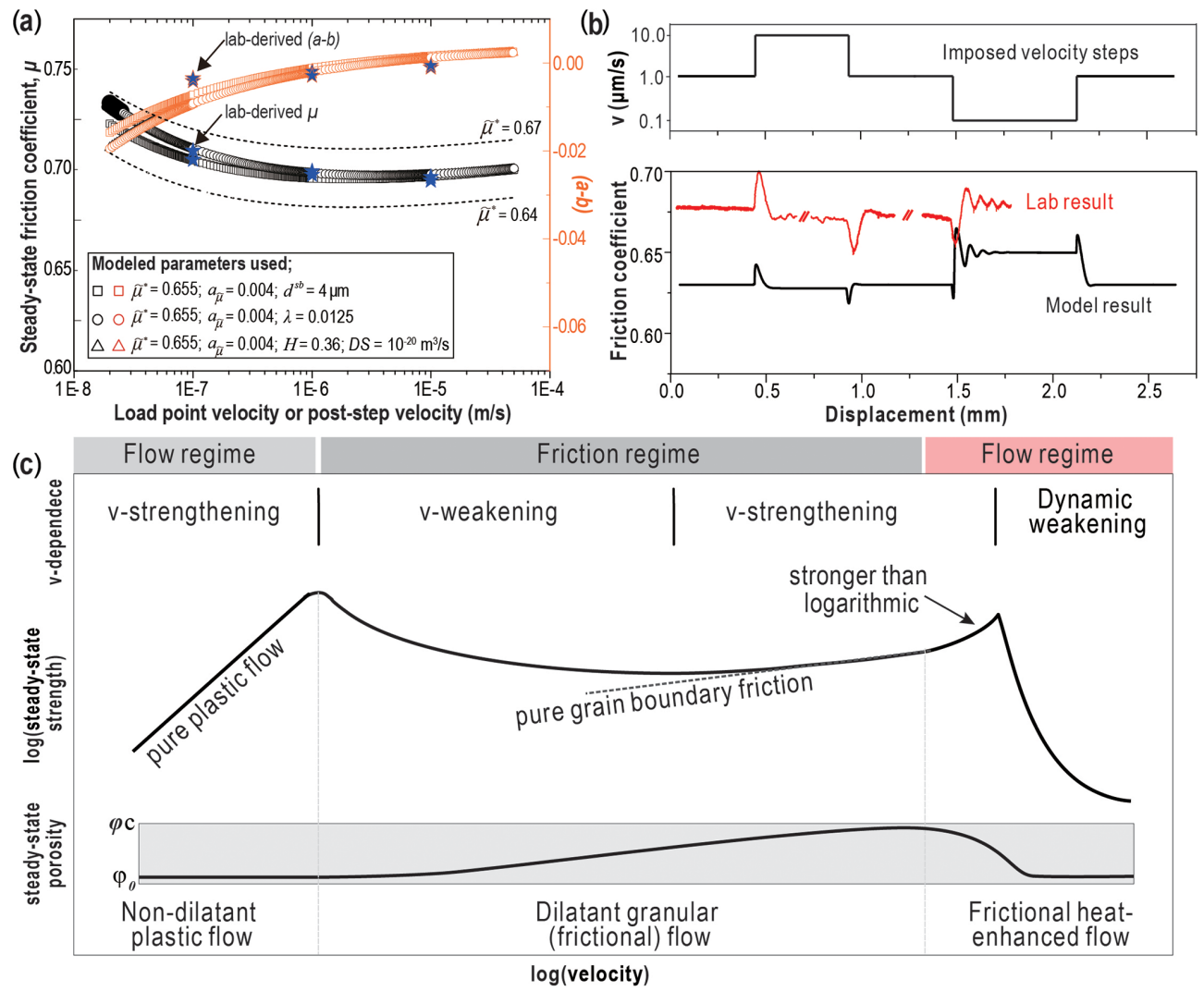

Figure 7. Reproduction of experimental data using the CNS model. (a) Steady-state frictional strength and ( $a-b)$ values, as well as (b) $v$-stepping tests. Data from experiments on calcite gouge performed at $T=80^{\circ} \mathrm{C}$ and $\sigma_{\mathrm{n}}^{\text {eff }}=50 \mathrm{MPa}$ (see Fig. 5a). (c) Model output for a wide range of fault sliding rates.
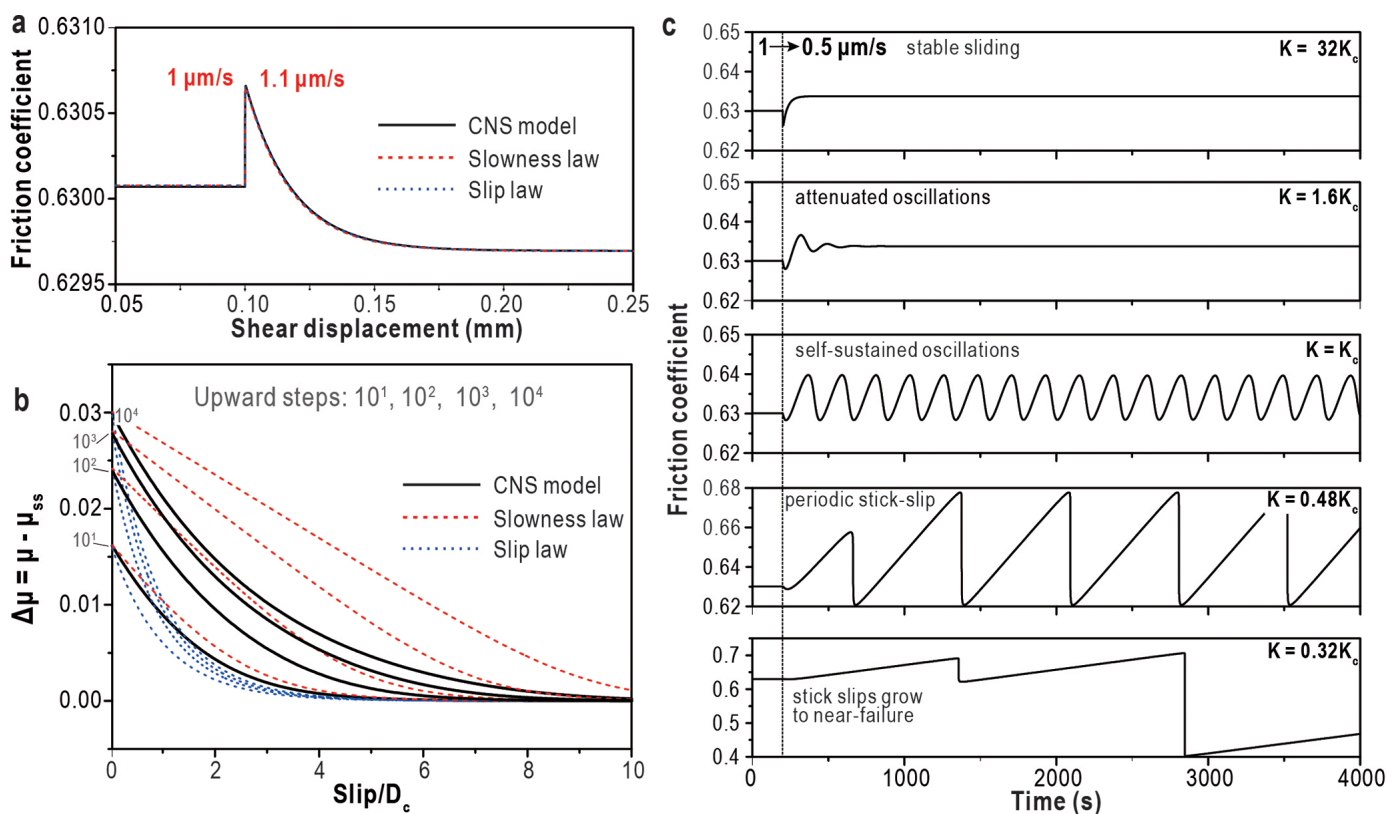

Figure 8. Comparison between CNS- and RSF-based models. (a) Small $\left(1 \rightarrow 1.1 \mu \mathrm{m} \mathrm{s}^{-1}\right.$ ) and large (up to 4 orders of magnitude) perturbations in sliding velocity (the upper and lower diagrams, respectively). The RSF parameter values used are the equivalent values calculated from the CNS model (see Chen et al., 2017). (b) CNS modelling of a velocity step $1 \rightarrow 0.5 \mu \mathrm{m} \mathrm{s}^{-1}$ for different stiffnesses $K$ (see Chen and Niemeijer, 2017). 

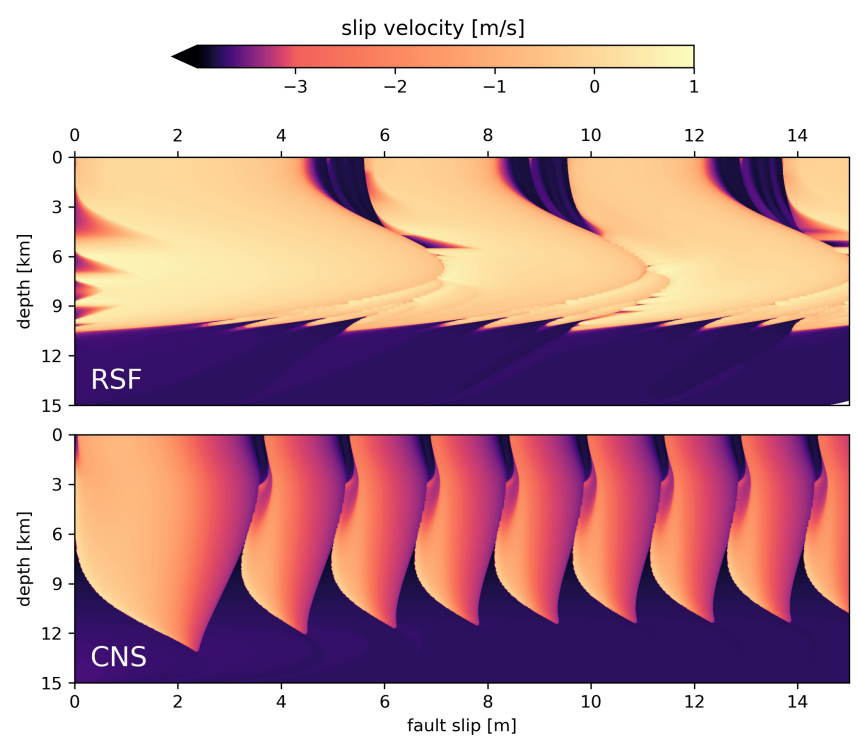

Figure 9. Numerical simulation of the spatio-temporal evolution of slip rates on a simulated strike-slip fault based on rate-and-state friction (RSF; top) and on the CNS model (bottom). Brighter colours indicate higher slip rates, and dark purple indicates slow creep. While the RSF-based simulation exhibits large and fast earthquakes, the CNS-based simulation exhibits mostly small slow-slip events. After Van den Ende et al. (2018).

and rheological conditions that control the spectrum of slip modes observed in nature.

Another example that highlights the major benefits of using a physically based constitutive relation in numerical simulations involves studies of fluid pressure stimulation of faults (see Van den Ende et al., 2020, this volume). In the case of fluid injection or extraction, the change in hydrological properties with time is crucial for modelling thermo-hydromechanical coupling in the system. For the RSF framework, empirical formulae have been proposed that describe the relation between volumetric deformation and evolution of the state variable, $\dot{\theta}$ (Segall and Rice, 1995; Shibazaki, 2005; Sleep, 2005; Samuelson et al., 2009). However, such a relation is not evident from the classical physical interpretation of $\theta$ as an asperity contact lifetime. In the CNS model, gouge porosity assumes the role of the state parameter, implying that its evolution can be directly related to changes in fluid pressure, effective normal stress, and/or hydrological properties within the fault (Van den Ende et al., 2020). To illustrate this, we simulate the evolution of porosity during nucleation, propagation, and arrest of a slow earthquake rupturing a onedimensional fault with uniform frictional properties (Fig. 10) for the regime in which dynamic high-velocity slip is not yet triggered. During the nucleation stage, the fault dilates and weakens simultaneously with accelerated slip. As the rupture reaches its peak slip rates, the gouge attains maximum dilatancy and minimum strength, after which the gouge compacts upon deceleration and rupture arrest. During this cycle
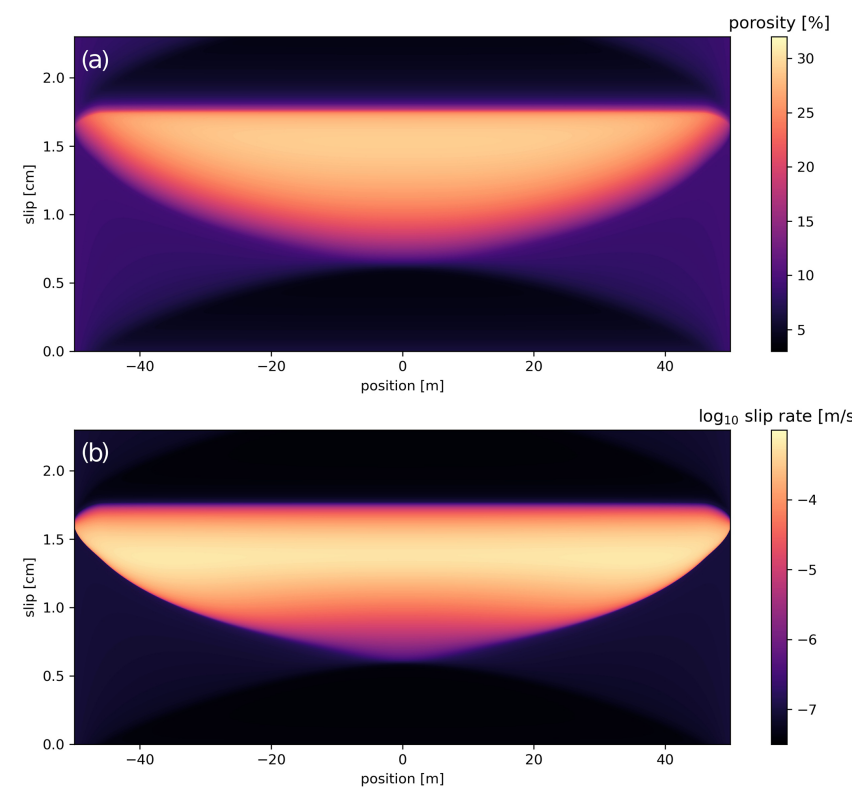

Figure 10. Spatio-temporal evolution of fault gouge porosity (a) and slip rate (b) during nucleation, propagation, and arrest of a rupture on a fault with uniform frictional properties. The rupture nucleates in the centre and propagates outwards.

of nucleation, propagation, and arrest, the hydrological properties (i.e. hydraulic conductivity) can be computed based on the local porosity. In turn, and informed by laboratory experiments, this enables investigation of the dynamic coupling between fluid flow and fault slip (e.g. Cappa et al., 2019).

\section{$7 \quad$ Remaining challenges}

To date, the microphysical and earthquake cycle modelling work described above has mainly focused on the interseismic and nucleation stages of the seismic cycle. For a complete and self-consistent description of fault deformation, co-seismic slip rates must be considered as well. However, the present model assumptions are reasonable for gouge shear deformation at low slip rates, but they break down when frictional heating and associated dynamic fault rupture processes come into play. Specifically, the model requires adaption to include heat production during deformation at the ultra-high shear strain rates $\left(\gg 100 \mathrm{~s}^{-1}\right)$ capable of triggering weakening processes such as thermal pressurization, decomposition, or melting (Rice, 2006; Di Toro et al., 2006, 2011; Platt et al., 2015). As described earlier in this paper, a first step in this direction has been made by Chen et al. (2019), who take into account slip-rate-dependent heat production coupled with temperature and grain size sensitivity of creep processes (see Fig. 7c) (see De Paola et al., 2015; Pozzi et al., 2019).

Another major challenge yet to be addressed in fault deformation models lies in capturing the dynamics of micro- 
and nanostructure formation in sheared fault rock. The CNS model adopts a constant granular structure (Fig. 6), implying that the thickness of the deforming zone and the grain size within must be defined a priori. This is problematic, for example, under conditions close to the transition with increasing strain rate or decreasing temperature from $v$ strengthening to $v$ weakening (ref. Fig. 7c). Microstructures from experiments on simulated calcite gouge at high temperatures $\left(500-600^{\circ} \mathrm{C}\right.$ ) point to the role of grain growth in addition to grain size reduction, suggestive of trade-offs between grain size, temperature, slip velocity, and localization (Verberne et al., 2015, 2017). Moreover, there is the additional complexity that the deformation properties of individual mineral particles can change with changing particle size. Constraining this is especially important in the case of nanometric gouges (grain size $<100 \mathrm{~nm}$ ), which, along with (partly) amorphized host rocks, are widespread in natural and experimentally sheared fault gouges (Power and Tullis, 1989; Yund et al., 1990; for a recent review see Verberne et al., 2019). Individual nanoparticles and nanocrystalline aggregates frequently exhibit dramatically different physical properties compared with their bulk counterparts (e.g. Meyers et al., 2006; Hochella et al., 2019) - the room-temperature ductile nanofibres encountered in calcite gouge being an example of this (Fig. 5c, inset) (Verberne et al., 2014b, 2019). The implication is that extrapolation of data from compaction experiments using micron-sized crystals or larger, which are used to constrain parameter values appearing in the CNS model, may lead to large errors when applied to nanogranular or (partly) amorphous fault rock.

Even when coarser-grained fault rocks are considered, frictional sliding on the contact between two grains is ultimately governed by nanometre-scale processes. This can be envisioned as lattice-scale solid-solid interactions for "dry" contacts or contacts with incomplete coatings of adsorbed species, such as water (used in the CNS model; Chen and Spiers, 2016), or as interactions arising from the unique properties of fully developed, adsorbed water or hydration layers (Leng and Cummings, 2006; Sakuma et al., 2018). Since the nanometric realm is inaccessible by standard observation techniques, directly probing the processes leading to grainscale friction remains challenging, in particular for the LVF tests described in Sect. 3. Instead, atomic force microscopy (AFM) experiments, also known as friction force microscopy (FFM; see Bennewitz, 2005 for a review), may provide critical observations of the sample response to variations in sliding rate, normal stress, and chemical environment (Diao and Espinosa-Marzal, 2018, 2019). These observations will inform nanophysical models in a similar way as grain- and aggregate-scale observations have informed the CNS model.

Finally, we note that the capability of the CNS model to fully describe the frictional behaviour of strongly heterogeneous gouge compositions, including transients, remains to be investigated. To date this has only been demonstrated for monomineralic calcite (Chen and Spiers, 2016; Chen et al.,
2017, 2020a, b). In the case that phyllosilicates constitute large portions of the fault gouge, the overall constitutive behaviour can no longer be represented by taking bulk mean values of rheological properties (pressure solution kinetics, grain size, etc.). Instead, the interactions between the various phases within the gouge need to be considered more closely in the assumed microphysical model geometry (e.g. Fig. 4b) or using numerical simulations that enable aggregate heterogeneity (using discrete or finite-element models; see Wang et al., 2019; Beall et al., 2019). While microphysical modelling of heterogeneous systems poses some challenges, its potential outcomes likely offer new insights on natural fault deformation, including on the problem of upscaling to more realistic fault geometries.

\section{Conclusions}

We reviewed experimental and microphysical modelling work on the physics of low-velocity fault friction processes carried out at Utrecht University (UU) since the early 2000s. Data from shear deformation experiments on simulated fault rocks composed of halite-phyllosilicate and phyllosilicatequartz mixtures, as well as of monomineralic calcite, consistently show that fault gouge strength and stability is controlled by competition between rate-sensitive creep and rate-insensitive granular flow processes. Under conditions in which ductile deformation occurs in the Earth's crust, fault shear deformation is non-dilatant and controlled purely by creep, which is intrinsically stable. However, towards shallower depths, frictional(-viscous) deformation occurs, which is controlled by creep of individual mineral grains operating alongside dilatant granular flow. The seismogenic zone represents a depth interval in the crust where these processes operate at comparable rates, $\left|\dot{\varepsilon}_{\text {dil }}\right| \approx\left|\dot{\varepsilon}_{\mathrm{cp}}\right|$, which leads to velocity weakening and hence seismogenic fault-slip behaviour. This conceptual model framework is quantitatively described by the Chen-Niemeijer-Spiers (CNS) model for shear of gouge-filled faults, which constitutes a physically based microphysical model that is capable of reproducing a wide range of (transient) frictional behaviours. Despite numerous challenges ahead on capturing deformation process active in slipping gouge-filled faults, including at co-seismic slip rates, the CNS model offers new microstructurally and physically founded input for earthquake cycle simulators and therewith new scope for the interpretation of earthquake source processes.

Data availability. All data are available from the papers cited or else upon request from the corresponding author. The QDYN seismic cycle simulator (including the implementation of the CNS model) is open-source and available from https://github.com/ydluo/ qdyn (Van den Ende et al., 2018; Luo et al., 2017, last access: 12 November 2020). 
Author contributions. BAV led the effort, drafted the initial paper, and wrote Sects. 1 and 3. BAV and MPAvdE co-wrote Sects. 2, 4, 7, and 8, with contributions by JC to Sect. 4. JC wrote Sect. 5 and MPAvdE Sect. 6. ARN and CJS helped through discussions and improved the final paper.

Competing interests. The authors declare that they have no conflict of interest.

Special issue statement. This article is part of the special issue "Thermo-hydro-mechanical-chemical (THMC) processes in natural and induced seismicity", dedicated to The 7th International Conference on Coupled THMC Processes, Utrecht, Netherlands, 3-5 July 2019.

Acknowledgements. The research work described in this paper would have been impossible without the support of Magda MathotMartens, Eimert de Graaff, Gert Kastelein, Thony van der GonNetscher, Peter van Krieken, Otto Stiekema, Leonard Bik, Floris van Oort, and Gerard Kuijpers. Colin Peach is thanked for his major scientific contributions throughout the years, as well as for developing, improving, and maintaining experimental equipment. Miki Takahashi is thanked for providing the photo in Fig. 2a.

Financial support. This work has been supported by the Japan Society for the Promotion of Science (KAKENHI grant no. 19K14823), the Government of France UCAJEDI (grant no. ANR15-IDEX-01), and the European Research Council (grant no. 335915).

Review statement. This paper was edited by Jean Sulem and reviewed by two anonymous referees.

\section{References}

Aharonov, E. and Scholz, C. H.: A physics-based rock friction constitutive law: steady-state friction, J. Geophys. Res., 123, 15911614, 2018.

Aharonov, E. and Scholz, C. H.: The brittle-ductile transition predicted by a physics-based friction law, J. Geophys. Res., 124, 2721-2737, 2019.

Ampuero, J.-P. and Rubin, A. M.: Earthquake nucleation on rate and state faults - Aging and slip laws, J. Geophys. Res., 113, B01302, https://doi.org/10.1029/2007JB005082, 2008.

Bakker, E., Hangx, S. J. T., Niemeijer, A. R., and Spiers. C. J.: Frictional behaviour and transport properties of simulated gouges derived from a natural $\mathrm{CO}_{2}$ reservoir, Int. J. Greenh. Gas Con. 54, 70-83, 2016.

Barbot, S.: Slow-slip, slow earthquakes, period-two cycles, full and partial ruptures, and deterministic chaos in a single asperity fault, Tectonophysics, 768, 228171, https://doi.org/10.1016/j.tecto.2019.228171, 2019.
Baumberger, T., Heslot, F., and Perrin, B.: Crossover from creep to intertial motion in friction dynamics, Nature, 367, 544-546, 1994.

Beall, A., Fagereng, Å., and Ellis, S.: Strength of strained twophase mixtures: Application to rapid creep and stress amplification in subduction zone mélange, Geophys. Res. Lett., 46, 169178, 2019.

Beeler, N. M., Tullis, T. E., Blanpied, M. L., and Weeks, J. D.: Frictional behavior of large displacement experimental faults, J. Geophys. Res., 101, 8697-8715, 1996.

Bennewitz, R.: Friction force microscopy, Mater today, 8, 42-48, https://doi.org/10.1016/S1369-7021(05)00845-X, 2005.

Blanpied, M. L., Lockner, D. A., and Byerlee, J. D.: Fault stability inferred from granite sliding experiments at hydrothermal conditions, Geophys. Res. Lett., 18, 609-612, 1991.

Blanpied, M. L., Lockner, D. A., and Byerlee, J. D.: Frictional slip of granite at hydrothermal conditions, J. Geophys. Res., 100, 13045-13064, 1995.

Bos, B. and Spiers, C. J.: Effect of phyllosilicates on fluid-assisted healing of gouge-bearing faults, Earth Planet. Sci. Lett., 184 199-210, 2000.

Bos, B. and Spiers, C. J. Experimental investigation into the microstructural and mechanical evolution of phyllosilicate-bearing fault rock under conditions favouring pressure solution, J. Struct. Geol., 23, 1187-1202, 2001.

Bos, B. and Spiers, C. J.: Frictional-viscous flow of phyllosilicatebearing fault rock: Microphysical model and implications for crustal strength profiles, J. Geophys. Res., 107, 2028, https://doi.org/10.1029/2001JB000301, 2002a.

Bos, B. and Spiers, C. J.: Fluid-assisted healing processes in gougebearing faults: Insights from experiments on a rock analogue system, Pure Appl. Geophys., 159, 2537-2566, 2002 b.

Bos, B., Peach, C. J., and Spiers, C. J.: Slip behavior of simulated gouge-bearing faults under conditions favoring pressure solution, J. Geophys. Res., 105, 16699-16717, 2000a.

Bos, B., Peach, C. J., and Spiers, C. J.: Frictional-viscous flow of simulated fault gouge caused by the combined effects of phyllosilicates and pressure solution, Tectonophysics, 327, 173-194, 2000b.

Boulton, C., Niemeijer, A. R., Hollis, C. J., Townend, J., Raven, M. D., Kulhanek, D. K., and Shepherd, C. L.: Temperaturedependent frictional properties of heterogeneous Hikurangi Subduction Zone input sediments, ODP Site 1124, Tectonophysics, 757, 123-139, 2019.

Bowden, F. P. and Tabor, D.: The Friction and Lubrication of Solids: Part I, Clarendon Press, Oxford, UK, 1950.

Bowden, F. P. and Tabor, D.: The Friction and Lubrication of Solids. Part II, Clarendon Press, Oxford, UK, 1964.

Brace, W. F. and Byerlee, J. D.: Stick slip as a mechanism for earthquakes, Science, 153, 990-992, 1966.

Brace, W. F. and Kohlstedt, D. L.: Limits on lithospheric stress imposed by laboratory experiments, J. Geophys. Res., 85, 62486252, 1980.

Bürgmann, R.: The geophysics, geology and mechanics of slow fault slip, Earth Planet. Sci. Lett., 495, 112-134, 2018.

Byerlee, J. D.: The mechanics of stick-slip, Tectonophysics, 9, 475486, 1970.

Byerlee, J. D.: Friction of rocks, Pure Appl. Geophys., 116, 615626, 1978. 
Cappa, F., Scuderi, M. M., Collettini, C., Guglielmi, Y., and Avouac, J.-P. Stabilization of fault slip by fluid injection in the laboratory and in situ, Sci. Adv., 5, eaau4065, https://doi.org/10.1126/sciadv.aau4065, 2019.

Chen, J. and Niemeijer, A. R.: Seismogenic potential of a gougefilled fault and the criterion for its slip stability: Constraints from a microphysical model, J. Geophys. Res., 122, 9658-9688, 2017.

Chen, J. and Spiers, C. J.: Rate and state frictional and healing behavior of carbonate fault gouge explained using microphysical model, J. Geophys. Res., 121, 8642-8665, 2016.

Chen, L., Xu, J., and Chen, J.: Applications of scanning electron microscopy in earth sciences, Sci. China Earth Sci., 58, 17681778, 2015a.

Chen, J., Verberne, B. A., and Spiers, C. J.: Interseismic restrengthening and stabilization of carbonate faults by "nonDieterich-type" healing under hydrothermal conditions, Earth Planet. Sci. Lett., 423, 1-12, 2015 b.

Chen, J., Verberne, B. A., and Spiers, C. J.: Effects of healing on the seismogenic potential of carbonate fault rocks: Experiments on samples from the Longmenshan Fault, Sichuan, China, J. Geophys. Res., 120, 5479-5506, 2015c.

Chen, J., Niemeijer, A. R., and Spiers, C. J.: Microphysically derived expressions for rate-and-state friction parameters, $\mathrm{a}, \mathrm{b}$, and D , J. Geophys. Res., 122, 9627-9657, 2017.

Chen, J., Niemeijer, A. R., and Spiers, C. J.: Microphysical modeling of carbonate fault friction: Extension from nucleation to seismic velocity, 7th International Conference of THMC Process, Utrecht University, the Netherlands, 3-5 July 2019.

Chen, J., Van den Ende, M. P. A., and Niemeijer, A. R.: Microphysical model predictions of fault restrengthening under room-humidity and hydrothermal conditions: From logarithmic to power-law healing, J. Geophys. Res., 125, e2019JB018567, https://doi.org/10.1029/2019JB018567, 2020a.

Chen, J., Verberne, B. A., and Niemeijer, A. R.: Flow-toFriction Transition in Simulated Calcite Gouge: Experiments and Microphysical Modelling, J. Geophys. Res., e2020JB019970, https://doi.org/10.1029/2020JB019970, 2020b.

Chester, F. M. and Logan, J. M.: Frictional faulting in polycrystalline halite: Correlative microstructure, mechanisms of slip, and constitutive behaviour, in: The brittle-ductile transition in rocks. Geophysical Monograph 56, edited by: Duba, A. G., Durham, W. B., Handin, J. W., and Wang, H. F., AGU (American Geophysical Union), Washington, DC, 49-65, 1990.

Collettini, C., Niemeijer, A. R., Viti, C., Smith, S. A. F., and Marone, C.: Fault structure, frictional properties and mixedmode fault slip behavior, Earth Planet. Sci. Lett., 311, 316-327, 2011.

Collettini, C., Tesei, T., Scuderi, M. M., Carpenter, B. M., and Viti, C.: Beyond Byerlee friction, weak faults and implications for slip behavior, Earth Planet. Sci. Lett., 519, 245-263, 2019.

De Paola, N., Holdsworth, R. E., Viti, C., Collettini, C., and Bullock, R. Can grain size sensitive flow lubricate faults during the initial stages of earthquake propagation?, Earth Planet. Sci. Lett., 431, 48-58, 2015.

De Winter, D. A. M., Schneijdenberg, C. W. T. M., Lebbink, M. N., Lich, B., Verkleij, A. J., Drury, M. R., and Humbel, B. M.: Tomography of insulating biological and geological materials using focused ion beam (FIB) and low-kV BSE imaging, J. Microsc., 233, 372-383, 2009.
Delle Piane, C., Piazolo, S., Timms, N. E., Luzin, V., Saunders, M., Bourdet, J., Giwelli, A, Clennell, M. B., Kong, C., Rickard, W. D. A., and Verrall, M.: Generation of amorphous carbon and crystallographic texture during low temperature subseismic slip in calcite fault gouge, Geology, 46, 163-166, https://doi.org/10.1130/G39584.1, 2018.

Den Hartog, S. A. M. and Spiers, C. J.: Influence of subduction zone conditions and gouge composition on frictional slip stability of megathrust faults, Tectonophysics, 600, 75-90, 2013.

Den Hartog, S. A. M. and Spiers, C. J.: A microphysical model for fault gouge friction applied to subduction megathrusts, J. Geophys. Res., 119, 1510-1529, 2014.

Den Hartog, S. A. M., Peach, C. J., De Winter, D. A. M., Spiers, C. J., and Shimamoto, T.: Frictional properties of megathrust fault gouges at low sliding velocities: New data on effects of normal stress and temperature, J. Struct. Geol., 38, 156-171, 2012a.

Den Hartog S. A. M., Niemeijer A. R., and Spiers C. J.: New constraints on megathrust slip stability under subduction zone P-T conditions, Earth Planet. Sci. Lett., 353-354, 240-252, 2012 b.

Den Hartog, S. A. M., Niemeijer, A. R., and Spiers, C. J.: Friction on subduction megathrust faults: Beyond the illite-muscovite transition, Earth Planet. Sci. Lett., 373, 8-19, 2013.

Den Hartog, S. A. M., Saffer, D. M., and Spiers, C. J.: The roles of quartz and water in controlling unstable slip in phyllosilicaterich megathrust fault gouges, Earth Planets Space, 66, 78, https://doi.org/10.1186/1880-5981-66-78, 2014.

Di Toro, G., Hirose, T., Nielsen, S., Pennacchioni, G., and Shimamoto, T.: Natural and experimental evidence of melt lubrication of faults during earthquakes, Science, 311, 647-649, 2006.

Di Toro, G., Han, R., Hirose, T., De Paola, N., Nielsen, S., Mizoguchi, K., Ferri, F., Cocco, M., and Shimamoto, T.: Fault lubrication during earthquakes, Nature, 471, 494-498, 2011.

Diao, Y. and Espinosa-Marzal, R. M.: The role of water in fault lubrication, Nat. Commun., 9, 2309 https://doi.org/10.1038/s41467-018-04782-9, 2018.

Diao, Y. and Espinosa-Marzal, R. M.: Effect of fluid chemistry on the interfacial composition, adhesion, and frictional response of calcite single crystals-Implications for injection-induced seismicity, J. Geophys. Res., 124, 5607-5628, 2019.

Dieterich, J. H.: Time-dependent friction and the mechanics of stick-slip, Pure Appl. Geophys., 116, 791-806, 1978.

Dieterich, J. H.: Modeling of rock friction 1. Experimental results and constitutive equations, J. Geophys. Res., 84, 2161-2168, 1979a.

Dieterich, J. H.: Modeling of rock friction 2. Simulation of preseismic slip, J. Geophys. Res., 84, 2169-2175, 1979 b.

Dieterich, J. H.: A constitutive law for rate of earthquake production and its application to earthquake clustering, J. Geophys. Res., 99, 2601-2618, 1994.

Dieterich, J. H. and Kilgore, B. D.: Direct observation of frictional contacts: New insights for state-dependent properties, Pure Appl. Geophys., 143, 283-302, 1994.

Elsworth, D., Spiers, C. J., and Niemeijer, A. R.: Understanding induced seismicity, Science, 354, 1380-1381, 2016.

Fagereng, A. and Den Hartog, S. A. M.: Subduction megathrust creep governed by pressure solution and frictional-viscous flow, Nat. Geosci., 10, 51-57, https://doi.org/10.1038/NGEO2857, 2016. 
Fagereng, Å., Hillary, G. W. B., and Diener, J. F. A.: Brittle-viscous deformation, slow slip, and tremor, Geophys. Res. Lett., 41, 4159-4167, https://doi.org/10.1002/2014GL060433, 2014.

Gao, X. and Wang, K.: Rheological separation of the megathrust seismogenic zone and episodic tremor and slip, Nature, 543, 416-419, 2017.

Grigoli, F., Cesca, S., Rinaldi, A. P., Manconi, A., López-Comino, J. A., Clinton, J. F., Westaway, R., Cauzzi, C., Dahm, T., and Wiemer, S.: The November 2017 Mw Pohang earthquake: A possible case of induced seismicity in South Korea, Science, 360, 1003-1006, 2018.

Gu, J. C., Rice, J. R., Ruina, A. L., and Tse, S. T.: Slip motion and stability of a single degree of freedom elastic system with rate and state dependent friction, J. Mech. Phys. Sol., 32, 167-196, 1984.

$\mathrm{Gu}, \mathrm{Y}$. and Wong, T.-F.: Development of shear localization in simulated quartz gouge: effect of cumulative slip and gouge particle size, Pure Appl. Geophys., 143, 387-423, 1994.

Gudehus, G.: Physical soil mechanics, Springer, Berlin and Heidelberg, Germany, 840 pp, 2011.

Guha-Sapir, D., Hoyois, P., Below, R., and Wallemacq, P.: Annual Disaster Statistical Review 2016: The numbers and trends, CRED, Brussels, 2016.

Hawthorne, J. C. and Rubin, A. M.: Laterally propagating slow slip events in a rate and state friction model with a velocityweakening to velocity-strengthening transition, J. Geophys. Res., 118, 3785-3808, 2013.

He, C., Wang. Z., and Yao, W.: Frictional sliding of gabbro gouge under hydrothermal conditions, Tectonophysics, 445, 353-362, 2007.

Heaton, T. H.: Evidence for and implications of self-healing pulses of slip in earthquake rupture, Phys. Earth. Planet. Int., 64, 1-20, 1990.

Heilbronner, R. and Keulen, N.: Grain size and grain shape analysis of fault rocks, Tectonophysics, 427, 199-216, 2006.

Hellebrekers, N., Niemeijer, A. R., Fagereng, Å., Manda, B., and Mvula, R. L. S.: Lower crustal earthquakes in the East African Rift System: Insights from frictional properties of rock samples from the Malawi rift, Tectonophysics, 20, 228167, https://doi.org/10.1016/j.tecto.2019.228167, 2019.

Hiraga, H. and Shimamoto, T.: Textures of sheared halite and their implications for the seismogenic slip of deep faults, Tectonophysics, 144, 69-86, 1987.

Hirauchi, K.-I., Den Hartog, S. A. M., and Spiers, C. J.: Weakening of the slab-mantle wedge interface due to metasomatic growth of talc, Geology, 41, 75-78, 2013.

Hirauchi, K.-I., Yoshida, Y., Yabe, Y., and Muto, J.: Slow stickslip failure in halite gouge caused by brittle-plastic fault heterogeneity, Geochem. Geophys. Geosys., 21, e2020GC009165, https://doi.org/10.1029/2020GC009165, 2020.

Hochella Jr., M. F., Mogk, D. W., Ramville, J., Allen, I. C., Luther, G. W., Marr, L. C., McGrail, P., Murayama, M., Qafoku, N. P., Rosso, K. M., Sahai, N., Schroeder, P. A., Vikesland, P., Westerhoff, P., and Yang, Y.: Natural, incidental, and engineered nanomaterials and their impacts on the Earth system, Science, 363, 1414, https://doi.org/10.1126/science.aau8299, 2019.

Holdsworth, R. E.: Weak faults-Rotten cores, Science, 303, 181$182,2004$.
Holdsworth, R. E., Stewart, M., Imber, J., and Strachan, R. A.: The structure and rheological evolution of reactivated continental shear zones: a review and case study, in: Continental reactivation and reworking, edited by: Miller, J. A., Holdsworth, R. E., Buick, I. S., and Hand, M., Geological Society, London, Spec. Publ., 184, 115-137, 2001.

Hunfeld, L., Niemeijer, A. R., and Spiers, C. J.: Frictional properties of simulated fault gouges from the seismogenic Groningen Gas Field under in situ P-T -chemical conditions, J. Geophys. Res., 122, 8969-8989, 2017.

Hunfeld, L. B., Chen, J., Niemeijer, A. R., and Spiers, C. J.: Temperature and gas/brine content affect seismogenic potential of simulated fault gouges derived from Groningen Gas Field caprock, Geophys. Geochem. Geosys., 20, 2827-2847, 2019.

Hunfeld, L. B., Chen, J., Hol, S., Niemeijer, A. R., and Spiers, C. J.: Healing behaviour of simulated fault gouges from the Groningen gas field and implications for induced fault reactivation, J. Geophys. Res., 125, e2019JB018790, https://doi.org/10.1029/2019JB018790, 2020.

Hyndman, R. D., Yamano, M., and Oleskevich, D. A.: The seismogenic zone of subduction thrust faults, Isl. Arc., 6, 244-260, 1997.

Ide, S.: Modeling fast and slow earthquakes at various scales, Proc. Jpn. Acad. Ser. B, 90, 259-277, 2014.

Ikari, M. J.: Laboratory slow slip events in natural geological materials, Geophys. J. Int., 218, 354-287, 2019.

Ikari, M. J., Marone, C., and Saffer, D. M.: On the relation between fault strength and frictional stability, Geology, 39, 83-86, 2011.

Ikari, M. J., Niemeijer, A. R., Spiers, C. J., Kopf, A., and Saffer, D.: Experimental evidence linking slip stability with seafloor lithology and topography at the Costa Rica convergent margin, Geology, 41, 891-894, 2013.

Ikari, M. J., Carpenter, B. M., and Marone, C.: A microphysical interpretation of rate- and state-dependence friction for fault gouge, Geochem. Geophys. Geosys., 17, 1660-1677, 2016.

Imber, J., Holdsworth, R. E., Smith, S. A. F., Jefferies, S. P., and Collettini, C.: Frictional-viscous flow, seismicity and the geology of weak faults: a review and future directions, in: The internal structure of fault zones: Implications for mechanical and fluid-flow properties, edited by: Wibberley, C. A. J., Kurz, W., Imber, J., Holdsworth, R., and Collettini, C., Geological Society, London, Spec. Publ., 299, 151-173, 2008.

Jefferies, S. P., Holdsworth, R. E., Wibberley, C. A. J., Shimamoto, T., Spiers, C. J., Niemeijer, A. R., and Lloyd, G. E.: The nature and importance of phyllonite development in crustal-scale fault cores: an example from the Median Tectonic Line, Japan, J. Struct. Geol., 28, 220-235, 2006.

Kaneko, Y., Avouac, J.-P., and Lapusta, N.: Towards inferring earthquake patterns from geodetic observations of interseismic coupling, Nat. Geosci., 3, 363-369, 2010.

Karato, S.-I.: Deformation of earth materials, Cambridge Univ. Press., Cambridge, UK, 2008.

King, G.: The accommodation of large strains in the upper lithosphere of the earth and other solids by self-similar fault systems: the geometrical origin of the b-value, Pure Appl. Geophys., 121, 761-815, 1983.

Kohlstedt, D. L., Evans, B., and Mackwell, S. J.: Strength of the lithosphere: Constraints imposed by laboratory experiments, J. Geophys. Res., 100, 17857-17602, 1995. 
Kong, C., Rickard, W. D. A., and Verrall, M.: Generation of amorphous carbon and crystallographic texture during low temperature subseismic slip in calcite fault gouge, Geology, 46, 163-166, https://doi.org/10.1130/G39584.1, 2018.

Kumar, P., Korkolis, E., Benzi, R., Denisov, D., Niemeijer, A., Schall, P., Toschi, F., and Trampert, J.: On interevent time distributions of avalanche dynamics, Sci. Rep., 10, 626, https://doi.org/10.1038/s41598-019-56764-6, 2020.

Kurzawski, R. M., Stipp, M., Niemeijer, A. R., Spiers, C. J., and Behrmann, J. H.: Earthquake nucleation in weak subducted carbonates, Nat. Geosci., 9, 717-722, 2016.

Kurzawski, R. M., Niemeijer, A. R., Stipp, M., Charpentier, D., Behrmann, J. H., and Spiers, C. J.: Frictional properties of subduction input sediments at an erosive convergent continental margin and related controls on décollement slip modes: The Costa Rica Seismogenesis Project, J. Geophys. Res., 123, 83858408, 2018.

Lapusta, N. and Rice, J. R.: Nucleation and early seismic propagation of small and large events in a crustal earthquake model, J. Geophys. Res., 108, 2205, https://doi.org/10.1029/2001JB000793, 2003.

Leeman, J. R., Saffer, D. M., Scuderi, M. M., and Marone, C.: Laboratory observations of slow earthquakes and the spectrum of tectonic fault slip modes, Nat. Commun., 7, 11104, https://doi.org/10.1038/ncomms11104, 2016.

Leng, Y. and Cummings, P. T.: Shear dynamics of hydration layers, J. Chem. Phys., 125, 104701, https://doi.org/10.1063/1.2335844, 2006.

Logan, J. M., Dengo, C. A., Higgs, N. G., and Wang, Z. Z.: Fabrics of experimental fault zones: Their development and relationship to mechanical behavior, in: Fault mechanics and transport properties in rocks, edited by: Evans, B. and Wong, T.-F., Academic Press, London, UK, pp. 33-68, 1992.

Lui, S. K. Y. and Lapusta, N.: Repeating microearthquake sequences interact predominantly through postseismic slip, Nat. Communs., 7, 13020, https://doi.org/10.1038/ncomms13020, 2016.

Luo, Y., Ampuero, J. P., Galvez, P., van den Ende, M., and Idini, B.: QDYN: a Quasi-DYNamic earthquake simulator (v1.1), Zenodo, https://doi.org/10.5281/zenodo.322459, 2017.

Marone, C.: Laboratory-derived friction laws and their application to seismic faulting, Annu. Rev. Earth Planet. Sci., 26, 643-696, 1998.

Marone, C. and Kilgore, B.: Scaling of the critical slip distance for seismic faulting with shear strain in fault zones, Nature, 362, 618-621, 1993.

Marone, C., Raleigh, C. B., and Scholz, C. H.: Frictional behavior and constitutive modeling of simulated fault gouge, J. Geophys. Res., 95, 7007-7026, 1990.

Masuda, K., Arai, T., and Takahashi, M.: Effects of frictional properties of quartz and feldspar in the crust on the depth extent of the seismogenic zone, Prog. Earth Planet. Sci., 6, 50, https://doi.org/10.1186/s40645-019-0299-5, 2019.

Matsuzawa, T., Hirose, H., Shibazaki, B., and Obara, K.: Modeling short- and long-term slow slip events in the seismic cycles of large subduction earthquakes, J. Geophys. Res., 115, B12301, https://doi.org/10.1029/2010JB007566, 2010.
Meissner, R. and Strehlau, J.: Limits of stresses in continental crusts and their relation to the depth-frequency distribution of shallow earthquakes, Tectonics, 1, 73-89, 1982.

Meyers, M. A., Mishra, A., and Benson, D. J.: Mechanical properties of nanocrystalline materials, Prog. Mater. Sci., 51, 427-556, 2006.

Niemeijer, A. R.: Velocity-dependent slip weakening by the combined operation of pressure solution and foliation development, Sci. Rep., 8, 4724, https://doi.org/10.1038/s41598-018-22889-3, 2018.

Niemeijer, A. R. and Collettini, C.: Frictional properties of a lowangle normal fault under in-situ conditions: Thermally-activated velocity weakening, Pure Appl. Geophys., 171, 2641-2664, 2014.

Niemeijer, A. R. and Spiers, C. J.: Influence of phyllosilicates on fault strength in the brittle-ductile transition: insights from rockanalogue experiments, in: High-strain zones: Structure and physical properties, edited by: Bruhn, D. and Burlini, L., Geol. Soc. London Spec. Publ., 245, 303-327, 2005.

Niemeijer, A. R. and Spiers, C. J.: Velocity dependence of strength and healing behaviour in simulated phyllosilicate-bearing fault gouge, Tectonophysics 427, 231-253, 2006.

Niemeijer, A. R. and Spiers, C. J.: A microphysical model for strong velocity weakening in phyllosilicatebearing fault gouges, J. Geophys. Res., 112, B10405, https://doi.org/10.1029/2007JB005008, 2007.

Niemeijer, A. R. and Vissers, R. L. M.: Earthquake rupture propagation inferred from the spatial distribution of fault rock frictional properties, Earth Planet. Sci. Lett., 396, 154-164, 2014.

Niemeijer, A. R., Spiers, C. J., and Peach, C. J.: Frictional behaviour of simulated quartz fault gouges under hydrothermal condition: Results from ultra-high strain rotary shear experiments, Tectonophysics, 460, 288-303, 2008.

Niemeijer, A., R., Di Toro, G., Griffith, W. A., Bistacchi, A., Smith, S. A. F., and Nielsen, S.: Inferring earthquake physics and chemistry using an integrated field and laboratory approach, J. Struct. Geol., 39, 2-36, 2012.

Niemeijer, A. R., Boulton, C., Toy, V. G., Townend, J., and Sutherland, R.: Large-displacement, hydrothermal frictional properties of DFDP-1 fault rocks, Alpine Fault, New Zealand: Implications for deep rupture propagation, J. Geophys. Res., 121, 624-647, 2016.

Nishikawa, T., Matsuzawa, T., Ohta, K., Uchida, N., Nishimura, T., and Ide, S.: The slow spectrum in the Japan Trench illuminated by the S-net seafloor observatories, Science, 365, 808-813, 2019.

Noda, H.: Implementation into earthquake sequence simulations of a rate- and state-dependent friction law incorporating pressure solution creep, Geophys. J. Int., 205, 1108-1125, 2016.

Noda, H. and Lapusta, N.: Stable creeping fault segments can become destructive as a result of dynamic weakening, Nature, 493, 518-521, 2013.

Ohtani, M., Hirahara, K., Hori, T., and Hyodo, M.: Observed change in plate coupling close to the rupture initiation area before the occurrence of the 2011 Tohoku earthquake: Implications from an earthquake cycle model, Geophys. Res. Lett., 41, 1899-1906, 2014.

Okamoto, A. S., Verberne, B. A., Niemeijer, A. R., Takahashi, M., Shimizu, I., Ueda, T., and Spiers, C. J.: Frictional properties of simulated chlorite gouge at hydrothermal conditions: Implica- 
tions for subduction megathrusts, J. Geophys. Res., 124, 45454565, 2019.

Okamoto, A. S., Niemeijer, A. R., Takeshita, T., Verberne, B. A., and Spiers, C. J.: Frictional properties of actinolite-chlorite gouge at hydrothermal conditions, Tectonophysics, 779, 228377, https://doi.org/10.1016/j.tecto.2020.228377, 2020.

Passelègue, F. X., Schubnel, A., Nielsen, S., Bhat, H. S., and Madariaga, R.: From sub-Rayleigh to supershear ruptures during stick-slip experiments on crustal rocks, Science, 340, 12081211, 2013.

Paterson, M. S.: A theory for granular flow accommodated by material transfer via an intergranular fluid, Tectonophysics, 245, 135151, 1995.

Peč, M., Stünitz, H., Heilbronner, R., and Drury, M.: Semi-brittle flow of granitoid fault rocks in experiments, J. Geophys. Res., 121, 1677-1705, 2016.

Peng, Z. and Gomberg, J.: An integrated perspective of the continuum between earthquakes and slow-slip phenomena, Nat. Geosci., 3, 599-607, 2010.

Platt, J., Brantut, N., and Rice, J. R.: Strain localization driven by thermal decomposition during seismic shear, J. Geophys. Res., 120, 4405-4433, 2015.

Pluymakers, A. M. H. and Niemeijer, A. R.: Healing and sliding stability of simulated anhydrite fault gouge: Effects of water, temperature, and $\mathrm{CO}_{2}$, Tectonophysics, 656, 111-130, 2015.

Pluymakers, A. M. H., Samuelson, J. E., Niemeijer, A. R., and Spiers, C. J.: Effects of temperature and $\mathrm{CO}_{2}$ on the frictional behavior of simulated anhydrite fault rock, J. Geophys. Res., 119, 8728-8747, 2014.

Power, W. L. and Tullis, T. E.: The relationship between slickenside surfaces in fine-grained quartz and the seismic cycle, J. Struct. Geol., 11, 4879-4893, 1989.

Pozzi, G., De Paola, N., Holdsworth, R. E., Bowen, L., Nielsen, S. B., and Dempsey, E. D.: Coseismic ultramylonites: An investigation of nanoscale viscous flow and fault weakening during seismic slip, Earth Planet. Sc. Lett., 516, 164-175, 2019.

Rabinowicz, E.: Autocorrelation analysis of the sliding process, J. Appl. Phys. 27, 131-135, 1956.

Rabinowicz, E.: The intrinsic variables affecting the stick-slip process. Proc. Phys. Soc. London, 71, 668-675, 1958.

Rattez, H. and Veveakis, M.: Weak phases production and heat generation control fault friction during seismic slip, Nat. Communs., 11, 350, https://doi.org/10.1038/s41467-019-14252-5, 2020.

Reber, J. E. and Peč, M.: Comparison of brittle- and viscous creep in quartzites: Implications for semibrittle flow of rocks, J. Struct. Geol., 113, 90-99, 2018.

Rempe, M., Smith, S. A. F., Mitchell, T., Hirose, T., and Di Toro, G.: The effect of water on strain localization in calcite fault gouge sheared at seismic slip rates, J. Struct. Geol., 97, 104-117, 2017.

Rice, J. R.: Heating and weakening of faults during earthquake slip, J. Geophys. Res., 111, B05311, https://doi.org/10.1029/2005JB004006, 2006.

Rice, J. R. and Ruina, A.: Stability of steady frictional slipping, J. Appl. Mech., 50, 343-349, 1983.

Rowe, C. D. and Griffith, W. A.: Do faults preserve a record of seismic slip: A second opinion, J. Struct. Geol. 78, 1-26, 2015.

Rubin, A. M.: Episodic slow slip events and rateand-state friction, J. Geophys. Res., 113, B11414, https://doi.org/10.1029/2008JB005642, 2008.
Rubin, A. M.: Designer friction laws for bimodal slow slip propagation speeds, Geochem. Geophys. Geosyst., 12, Q04007, https://doi.org/10.1029/2010GC003386, 2011.

Rubin, A. M. and Ampuero, J.-P.: Earthquake nucleation on (aging) rate and state faults, J. Geophys. Res., 110, B11312, https://doi.org/10.1029/2005JB003686, 2005.

Ruina, A.: Slip instability and state variable friction laws, J. Geophys. Res., 88, 10359-10370, 1983.

Rutter, E. H. and Mainprice, D. H.: On the possibility of slow fault slip controlled by a diffusive mass transfer process, Gerlands Beitr. Geophys., 88, 154-162, 1979.

Sakuma, H., Kawai, K., Katayama, I., and Suehara, S.: What is the origin of macropscopic friction?, Sci. Adv., 4, eaav2268, https://doi.org/10.1126/sciadv.aav2268, 2018.

Samuelson, J. E. and Spiers, C. J.: Fault friction and slip stability not affected by $\mathrm{CO}_{2}$ : Evidence from short-term laboratory experiments on North Sea reservoir sandstones and caprocks, Int. J. Greenh. Gas Con., 11, 78-90, https://doi.org/10.1016/j.ijggc.2012.09.018, 2012.

Samuelson, J. E., Elsworth, D., and Marone, C.: Shearinduced dilatancy of fluid-saturated faults: Experiment and theory, J. Geophys. Res., 114, B12404, https://doi.org/10.1029/2008JB006273, 2009.

Sánchez-Roa, C., Jiménez-Millán, J., Abad, I., Faulkner, D. R., Nieto, F., and García-Tortosa, F. J.: Fibrous clay mineral authigenesis induced by fluid-rock interaction in the Galera fault zone (Betic Cordillera, SE Spain) and its influence on fault gouge frictional properties, Appl. Clay Sci., 134, 275-288, 2016.

Sawai, M., Niemeijer, A. R., Plümper, O., Hirose, T., and Spiers, C. J.: Nucleation of frictional instability caused by fluid pressurization in subducted blueschist, Geophys. Res. Lett., 43, 2543 2551, 2016.

Sawai, M., Niemeijer, A. R., Hirose, T., and Spiers, C. J.: Frictional properties of JFAST core samples and implications for slow earthquakes at the Tohoku subduction zone, Geophys. Res. Lett., 44, 8822-8831, 2017.

Scholz, C. H.: The brittle-plastic transition and the depth of seismic faulting, Geol. Rund., 77, 319-328, 1988.

Scholz, C. H.: Earthquakes and friction laws, Nature, 391, 37-42, 1998.

Scholz, C. H.: The mechanics of earthquakes and faulting (3rd edition), Cambridge University Press, Cambridge, UK, 2019.

Scholz, C. H., Wyss, M., and Smith, S. W.: Seismic and aseismic slip on the San Andreas Fault, J. Geophys. Res., 74, 2049-2069, 1969.

Segall, P. and Rice, J. R.: Dilatancy, compaction, and slip instability of a fluid-infiltrated fault, J. Geophys. Res., 100, 22155-22171, 1995.

Shibazaki, B. and Iio, Y.: On the physical mechanisms of silent slip events along the deeper part of the seismogenic zon, Geophys. Res. Lett., 20, 1489, https://doi.org/10.1029/2003GL017047, 2003.

Shibazaki, B.: Nucleation process with dilatant hardening on a fluid-infiltrated strike-slip fault model using a rate- and state-dependent friction law, J. Geophys. Res., 110, B11308, https://doi.org/10.1029/2005JB003741, 2005.

Shimamoto, T.: Transition between frictional slip and ductile flow for halite shear zones at room temperature, Science, 231, 711714, 1986. 
Sibson, R. H.: Fault zone models, heat flow, and the depth distribution of earthquakes in the continental crust of the united states, Bull. Seismol. Soc. Am., 72, 151-163, 1982.

Sibson, R. H.: Continental fault structure and the shallow earthquake source, J. Geol. Soc. London, 140, 741-767, 1983.

Sibson, R. H.: Thickness of the seismic slip zone, Bull. Seismol. Soc. Am., 93, 1169-1178, 2003.

Siman-Tov, S., Aharonov, E., Sagy, A., and Emmanuel, S.: Nanograins from carbonate "fault mirrors", Geology, 41, 703706, 2013.

Simons, M., Minson, S. E., Sladen, A., Ortega, F., Jiang, J., Owen, S. E., Meng, L., Ampuero, J.-P., Wei, S., Chu, R., Helmberger, D. V., Kanamori, H., Hetland, E., Moore, A. W., and Webb, F. H.: The 2011 magnitude 9.0 Tohoku-Oki Earthquake: Mosaicking the megathrust from seconds to centuries, Science, 332, 14211426, 2011.

Sleep, N. H.: Physical basis of evolution laws for rate and state friction, Geochem. Geophys., 6, Q11008, https://doi.org/10.1029/2005GC000991, 2005.

Smith, S. A. F., Di Toro, G., Kim, S., Ree, J.-H., Nielsen, S., Billi, A., and Spiess, R.: Coseismic recrystallization during shallow earthquake slip, Geology, 41, 63-66, 2013.

Spiers, C. J. and Schutjens, P. M. T. M.: Densification of crystalline aggregates by fluid-phase diffusional creep, in: Deformation processes in minerals, ceramics and rocks, edited by: Barber, D. J. and Meredith, P. G., Mineralogical Society Ser. 1, Unwyn Hyman, London, 334-353, 1990.

Spiers, C. J., Schutjens, P. M. T. M., Brzesowsky, R. H., Peach, C. J., Liezenberg, J. L., and Zwart, H. J.: Experimental determination of constitutive parameters governing creep of rocksalt by pressure solution, in: Deformation mechanisms, Rheology and Tectonics, edited by: Knipe, R. J. and Rutter, E. H., Geological Society, London, Spec. Publ. 54, 215-227, 1990.

Takahashi, M., Van den Ende, M. P. A., Niemeijer, A. R., and Spiers, C. J.: Shear localization in a mature mylonitic rock analog during fast slip, Geochem. Geophys. Geosys., 18, 513-530, 2017.

Takeshita, T. and El-Fakharani, A.-H.: Coupled micro-faulting and pressure solution creep overprinted on quartz schists deformed by intracrystalline plasticity during exhumation of the Sambagawa metamorphic rocks, southwest Japan, J. Struct. Geol., 46, 142-157, 2013.

Tchalenko, J. S.: Similarities between shear zones of different magnitudes, Geol. Soc. Am. Bull., 81, 1625-1640, 1970.

Tenthorey, E. and Cox, S. F.: Cohesive strengthening of fault zones during the interseismic period: An experimental study, J. Geophys. Res., 111, B09202, https://doi.org/10.1029/2005JB004122, 2006.

Thomas, M. Y., Avouac, J.-P., and Lapusta, N.: Rate-and-state friction properties of the Longitudinal Valley Fault from kinematic and dynamic modeling of seismic and aseismic slip, J. Geophys. Res., 122, 3115-3137, 2017.

Tinti, E., Bizarri, A., and Cocco, M.: Modelling the dynamic rupture propagation on heterogeneous faults with rate- and statedependent friction, Ann. Geophys., 48, 327-345, 2005.

Tse, S. T. and Rice, J. R.: Crustal earthquake instability in relation to the depth variation of frictional slip properties, J. Geophys. Res., 91, 9452-9472, 1986.
Ulrich, T., Gabriel, A.-A., Ampuero, J.-P., and Xu, W.: Dynamic viability of the $2016 \mathrm{Mw} 7.8$ Kaikōura earthquake cascade on weak crustal faults, Nat. Communs., 10, 1-16, 2019.

Van den Ende, M. P. A. and Niemeijer, A. R.: Time-dependent compaction as a mechanism for regular stick-slips, Geophys. Res. Lett., 45, 5959-5967, 2018.

Van den Ende, M. P. A. and Niemeijer, A. R.: An investigation into the role of time-dependent cohesion in interseismic fault restrengthening, Sci. Rep., 9, 9894, https://doi.org/10.1038/s41598-019-46241-5, 2019.

Van den Ende, M. P. A., Chen, J., Ampuero, J. P., and Niemeijer, A. R.: A comparison between rate-and-state friction and microphysical models, based on numerical simulations of fault slip, Tectonophysics, 733, 273-295, 2018.

van den Ende, M. P. A., Scuderi, M. M., Cappa, F., and Ampuero, J.-P.: Extracting microphysical fault friction parameters from laboratory- and field injection experiments, Solid Earth Discuss., https://doi.org/10.5194/se-2020-118, in review, 2020.

Van Diggelen, E. W. E., De Bresser, J. H. P., Peach, C. J., and Spiers, C. J.: High shear strain behaviour of synthetic muscovite fault gouges under hydrothermal conditions, J. Struct. Geol. 32, 1685$1700,2010$.

Verberne, B. A., de Bresser, J. H. P., Niemeijer, A. R., Spiers, C. J., De Winter, D. A. M., and Plümper, O.: Nanocrystalline slip zones in calcite fault gouge show intense crystallographic preferred orientation: Crystal plasticity at sub-seismic slip rates at 18-150 ${ }^{\circ} \mathrm{C}$, Geology, 41, 863-866, 2013.

Verberne, B. A., Spiers, C. J., Niemeijer, A. R., De Bresser, J. H. P., De Winter, D. A. M., and Plümper, O.: Frictional properties and microstructure of calcite-rich fault gouges sheared at sub-seismic sliding velocities, Pure Appl. Geophys., 171, 2617-2640, 2014a.

Verberne, B. A., Plümper, O., De Winter, D. A. M., and Spiers, C. J.: Superplastic nanofibrous slip zones control seismogenic fault friction, Science, 346, 1342-1344, 2014b.

Verberne, B. A., Niemeijer, A. R., De Bresser, J. H. P., and Spiers, C. J.: Mechanical behavior and microstructure of simulated calcite fault gouge sheared at $20-600{ }^{\circ} \mathrm{C}$ : Implications for natural faults in limestones, J. Geophys. Res., 120, 8169-8196, 2015.

Verberne, B. A., Chen, J., Niemeijer, A. R., de Bresser, J. H. P., Pennock, G. M., Drury, M. R., and Spiers, C. J.: Microscale cavitation as a mechanism for nucleating earthquakes at the base of the seismogenic zone, Nat. Commun., 8, 1645, https://doi.org/10.1038/s41467-017-01843-3, 2017.

Verberne, B. A., Plümper, O., and Spiers, C. J.: Nanocrystalline principal slip zones and their role in controlling crustal fault rheology, Minerals, 9, 328, https://doi.org/10.3390/min9060328, 2019.

Viti, C.: Exploring fault rocks at the nanoscale, J. Struct. Geol., 33, 1715-1727, 2011.

Wallis, D., Lloyd, G. E., Phillips, R. J., Parsons, A. J., and Walshaw, R. D.: Low effectiv1715e fault strength due to frictional-viscous flow in phyllonites, Karakoram Fault Zone, NW India, J. Struct. Geol., 77, 45-61, 2015.

Wang, C., Elsworth, D., and Fang, Y.: Ensemble shear strength, stability, and permeability of mixed mineralogy fault gouge recovered from 3D granular models, J. Geophys. Res., 124, 425-441, 2019. 
Wintsch, R. P., Christoffersen, R., and Kronenberg, A. K.: Fluidrock reaction weakening of fault zones, J. Geophys. Res., 100, 13021-13032, 1995.

Yamashita, F., Fukuyama, E., Mizoguchi, K., Takizawa, S., Xu, S., and Kawakata, H.: Scale dependence of rock friction at high work rate, Nature, 528, 254-257, 2015.

Yao, L., Ma, S., Platt, J. D., Niemeijer, A. R., and Shimamoto, T.: The crucial role of temperature in high-velocity weakening of faults: Experiments on gouge using host blocks with different thermal conductivities, Geology, 44, 63-66, 2016.
Yoshioka, S., Suminokura, Y., Matsumoto, T., and Nakajima, J.: Two-dimensional thermal modelling of subduction of the Philippine Sea plate beneath southwest Japan, Tectonophysics, 608, 1094-1108, 2013.

Yund, R. A., Blanpied, M. L., Tullis, T. E., and Weeks, J. D.: Amorphous material in high-strain experimental fault gouges, J. Geophys. Res., 95, 15589-15602, 1990. 